San Jose State University

SJSU ScholarWorks

Master's Theses

Master's Theses and Graduate Research

1992

\title{
A comparison of speech and language test scores and spontaneous speech samples in drug exposed and non-drug exposed preschool-age children
}

Frances Cahn

San Jose State University

Follow this and additional works at: https://scholarworks.sjsu.edu/etd_theses

\section{Recommended Citation}

Cahn, Frances, "A comparison of speech and language test scores and spontaneous speech samples in drug exposed and non-drug exposed preschool-age children" (1992). Master's Theses. 294.

DOI: https://doi.org/10.31979/etd.hsn7-62eg

https://scholarworks.sjsu.edu/etd_theses/294

This Thesis is brought to you for free and open access by the Master's Theses and Graduate Research at SJSU ScholarWorks. It has been accepted for inclusion in Master's Theses by an authorized administrator of SJSU ScholarWorks. For more information, please contact scholarworks@sjsu.edu. 


\section{INFORMATION TO USERS}

This manuscript has been reproduced from the microfilm master. UMI films the text directly from the original or copy submitted. Thus, some thesis and dissertation copies are in typewriter face, while others may be from any type of computer printer.

The quality of this reproduction is dependent upon the quality of the copy submitted. Broken or indistinct print, colored or poor quality illustrations and photographs, print bleedthrough, substandard margins, and improper alignment can adversely affect reproduction.

In the unlikely event that the author did not send UMI a complete manuscript and there are missing pages, these will be noted. Also, if unauthorized copyright material had to be removed, a note will indicate the deletion.

Oversize materials (e.g., maps, drawings, charts) are reproduced by sectioning the original, beginning at the upper left-hand corner and continuing from left to right in equal sections with small overlaps. Each original is also photographed in one exposure and is included in reduced form at the back of the book.

Photographs included in the original manuscript have been reproduced xerographically in this copy. Higher quality 6" $\times 9$ " black and white photographic prints are available for any photographs or illustrations appearing in this copy for an additional charge. Contact UMI directly to order.

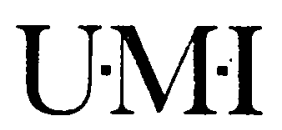

University Microfilms International

A Bell \& Howell Information Company

300 North Zeeb Road, Ann Arbor. MI 48106-1346 USA

$313 / 761-4700 \quad 800 / 521-0600$ 


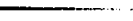

$\ldots$ 
Order Number 1848655

A comparison of speech and language test scores and spontaneous speech samples in drug exposed and non-drug exposed preschool-age children

Cahn, Frances M., M.A.

San Jose State University, 1992

$\mathrm{U} \cdot \mathrm{M} \cdot \mathrm{I}$

300 N. Zeeb Rd.

Ann Arbor, MI 48106 


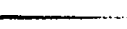

2....... 


\title{
A COMPARISON OF SPEECH AND LANGUAGE TEST SCORES \\ AND SPONTANEOUS SPEECH SAMPLES \\ IN DRUG EXPOSED AND NON-DRUG EXPOSED \\ PRESCHOOL-AGE CHILDREN
}

\author{
A Thesis \\ Presented to \\ The Faculty of the Division of \\ Special Education and Rehabilitative Services \\ Program in Communication Disorders and Sciences \\ San Jose State University \\ In Partial Fulfillment \\ of the Requirements for the Degree \\ Master of Arts \\ By \\ Frances Cahn \\ August, 1992
}




\section{APPROVED FOR THE DIVISION OF SPECIAL}

EDUCATION AND REHABILITATIVE SERVICES PROGRAM IN COMMUNICATION DISORDERS AND SCIENCES
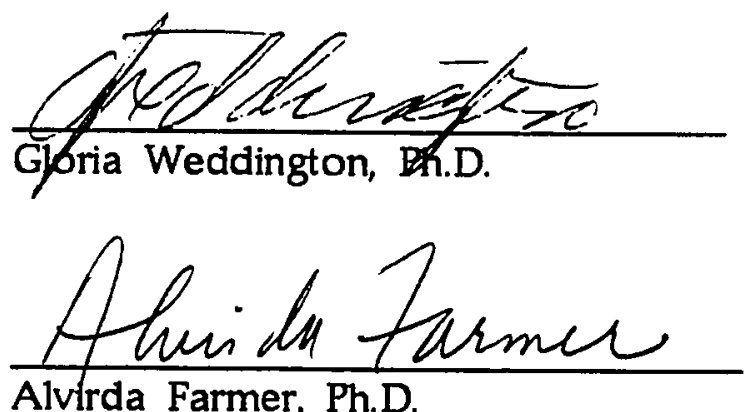
Alvirda Farmer, Ph.D.

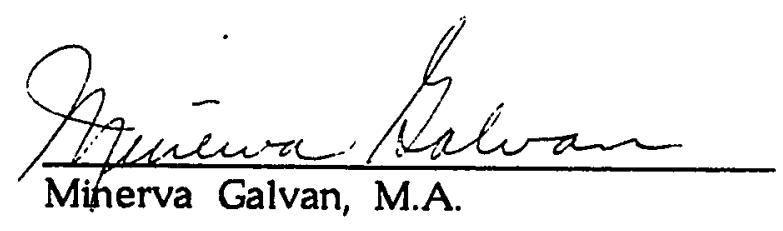

\section{APPROVED FOR THE UNIVERSITY}

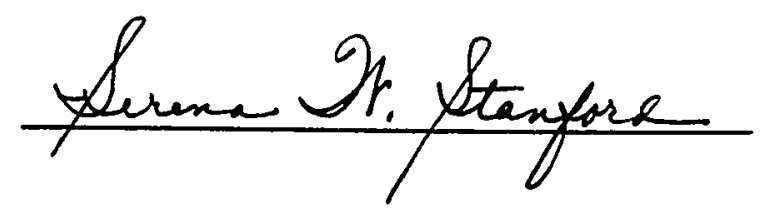




\section{ABSTRACT \\ A COMPARISON OF SPEECH AND LANGUAGE TEST SCORES AND SPONTANEOUS SPEECH SAMPLES IN DRUG EXPOSED AND NON-DRUG EXPOSED PRESCHOOL-AGE CHILDREN}

by Frances M. Cahn

This thesis investigates the relationship between scored spontaneous speech samples and speech and language test scores in preschool-age children. Test scores and speech samples of 10 children who were prenatally exposed to toxic substances were compared with those of 10 children who were not prenatally exposed to toxic substances.

This study reveals that while all 20 children were from similar family situations and were identified as being at risk for learning and/or behavioral problems, only those 10 children who were prenatally exposed to drugs displayed deficits in their spontaneous speech production. Therefore, it appears that standardized speech and language test scores may not accurately reflect exposed children's spontaneous speech production abilities and that age-equivalent or near age-equivalent expressive language test scores for exposed children do not necessarily imply that these children will have age equivalent conversation skills. 


\section{ACKNOWLEDGMENTS}

I would like to thank Dr. Gloria Weddington, Dr. Alvirda Farmer, and Minerva Galvan, M.A., for their concise and insightful comments during the preparation of this thesis. Their expertise in a variety of speech and language disciplines was crucial to our joint appreciation of the many variables involved. I would also like to express my gratitude to the children, parents, and staff at the We Care Center for their cooperation and interest in the testing procedures. Finally, my husband, Robert N. Cahn, and my daughters, Deborah and Sarah Cahn, deserve accolades for the time and effort spent in support of this project. 
TABLE OF CONTENTS

\section{Page}

LIST OF TABLES vii LIST OF FIGURES viii Chapter

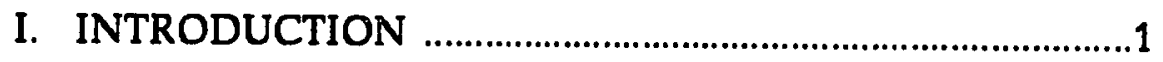

Statement of the Problem..........................................................

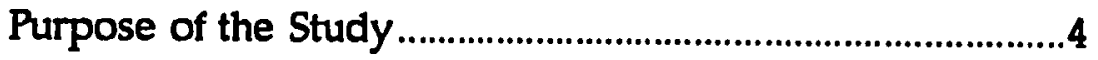

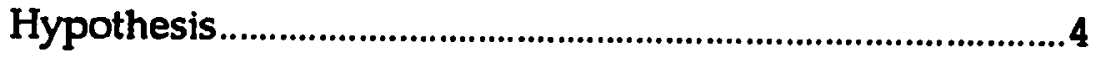

Definition of Terms.....................................................................

Assessment Measures............................................................

2. REVIEW OF THE LITERATURE .........................................13

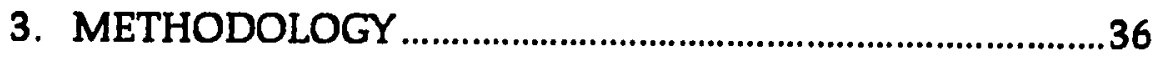

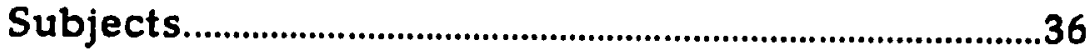

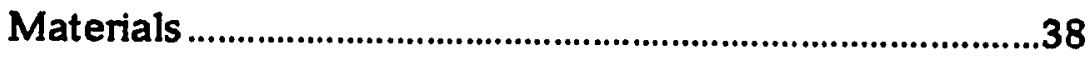

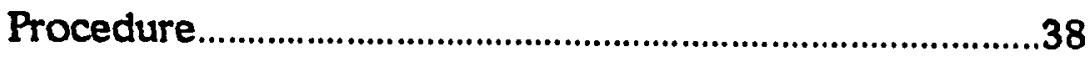

Statistical Measures ….............................................................40

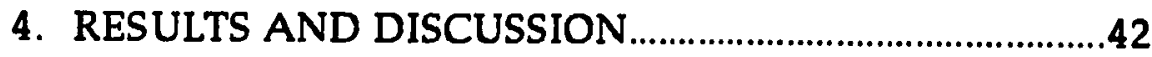

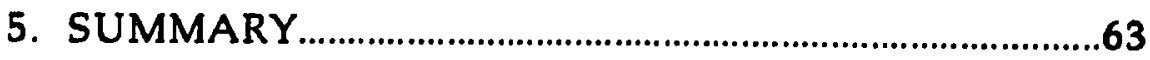

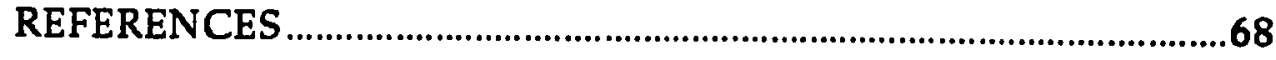


APPENDIXES.

A. Informational Letter

B. Consent Letter 


\section{LIST OF TABLES}

Table Page

1. Characteristics of Children Tested...................................................43

2. Individual Scores on Different Tests.............................................44

3. Correlation Matrix for Variables Considered in the Study............48

4. Partial Correlation Matrix with Influence of Drug Exposure

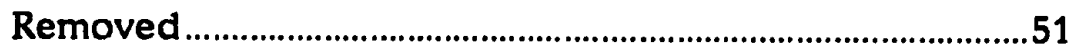

5. Analysis of Variance (ANOVA) .................................................52 


\section{LIST OF FIGURES}

Figure

1. Performance of drug-exposed and non-exposed children on the DSS and the PPVT-R

2. Performance of drug-exposed and non-exposed

children on the DSS and EOWPVT

3. Performance of drug-exposed and non-exposed children on the DSS and the SICD - Receptive Scale .56

4. Performance of drug-exposed and non-exposed children on the DSS and the SICD - Expressive Scale.

5. Performance of children from single or non-single parent homes on the DSS and the PPVT-R.

6. Performance of children from single or non-single parent homes on the DSS and the EOWPVT.

7. Performance of children from single or non-single parent homes on the DSS and the SICD - Receptive Scale.

8. Performance of children from single and non-single parent homes on the DSS and the SICD - Expressive Scale.

9. Performance of children from foster and non-foster homes on the DSS and the PPVT-R. 
10. Performance of children from foster and non-foster homes on the DSS and the EOWPVT...................................59

11. Performance of children from foster and non-foster homes on the DSS and the SICD - Receptive Scale...............60

12. Performance of children from foster and non-foster homes on the DSS and the SICD - Expressive Scale.

13. Performance of children from lower and middle class homes on the DSS and the PPVT-R....................................61

14. Performance of children from lower and middle class homes on the DSS and the EOWPVT

15. Performance of children from lower and middle class homes on the DSS and the SICD - Receptive Scale...............62

16. Performance of children from lower and middle class homes on the DSS and the SICD - Expressive Scale 


\section{CHAPTER 1}

Introduction

The number of children born to substance abusing mothers is known to be increasing in this country and is crossing all social, economic, and demographic lines (Lewis, 1991). Professionals, including those in the health, medical, education, criminal justice, and social studies fields have been documenting the adverse effects on these exposed infants. Many exposed infants are ill at birth and are difficult to care for when they are released from the hospital, due to behavioral, neurological, feeding, and sleeping disorders (Brazelton, 1990). Many remain hospitalized for weeks, months, or years due to respiratory, gastrointestinal, and other ailments, including Fallure-toThrive. A large percentage are placed immediately in foster care while their mother satisfies minimum requirements for the retum of her child, such as completing a drug withdrawal program and securing a stable place of residence (Schorr, 1989).

Foster care looms large in the exposed infant's life. As many addicted mothers are unable to maintain drug independence, the child may again be removed from its mother's care. Some foster children experience instability in the foster care system. Foster families, for personal reasons, may decide they are unable to keep the child. The infant may require special care and services due to medical and learning disabilities caused prenatally by drugs; the foster family may be overwhelmed by the demands and needs of such a child and will request a transfer. Thus the drug-exposed infant may face multiple transfers over the years and lack the consistency of a single caregiver or residence. 
In addition to the devastation caused by a lack of consistent parenting and the neurophysiologic prenatal insult of the drugs, the drug-exposed child's outlook is compromised by other factors (Schorr, 1989). An exposed infant may have been born to a woman who had poor nutrition and little or no prenatal care. The developing fetus may be small for gestational age and be susceptible to infections prior to, during, and after birth.

The child is a prime target for neglect and abuse, especially if he or she remains with a mother who is unable to control her drug habit. The infant's basic needs for care and feeding, combined with irritability, over-stimulability and/or lack of responsiveness compound the difficulty of the situation (Lewis, 1991).

Fraiberg (1967) wrote that children, who have been deprived of mothering and who have not formed strong personal human bonds by age 2 , display lasting impairments in the ability to develop human attachments. Lewis (1991) stated that attachment to significant others is critical for the child's social-emotional, behavioral, and language development to proceed normally. Numerous studies have been performed comparing exposed babies with non-exposed infants to measure the effects and to calculate the risks of drug exposure. Separating the specific drug effects (such as higher mortality at birth, prematurity, low birthweight, congenital defects and other health problems, and learning problems) from the social factors which may also be involved is difficult but seems to have been overcome in most reports of research. Many researchers have mentioned the diversity of outcomes in the children who had central nervous system insults due to drugs. The diversity, it is claimed, reflects primarily the amount, duration, and timing of 
the prenatal drug exposure, as well as the individual differences in the resiliency of the fetus. However, all the studies reviewed in this investigation expose the vulnerability of the fetus, despite the differences in individual susceptibility, and the universal contribution of drugs to developmental disruptions.

\section{Statement of the Problem}

Speech-language pathologists who work with children, whether in private practice, hospitals, clinics, residential and day treatment centers, or schools are asked to evaluate and treat communication disorders in drug-exposed children. In some cases, the exposure will be documented; in others, the clinician will have no information about the child's prenatal history. While it may not be feasible to develop a speech-language assessment battery which would reveal signs of a child's past drug exposure, it may be useful to research relationships between tests that are given to children to search for patterns which would indicate a disability and a need for remediation.

The fact that a child performs well on picture vocabulary tests which measure expressive and receptive language, but performs poorly in spontaneous speech may not be a symptom of a disorder traditionally associated with this disparity: developmental apraxia, emotional-social immaturity, extreme shyness, mental instability, and expressive aphasia are among those disorders which come to mind. Another category in this list could be "sequella of prenatal exposure to illicit drugs." In fact, science may ultimately determine that prenatal illicit drug exposure gives rise to forms of apraxia, aphasia, and/or emotional instability in young children, and that 
disparities in speech and language test scores may be symptomatic. The speech-language pathologist who finds such results from testing a young child should be alerted, however, to the possibility that drug exposure may have been involved. While remaining cautious and circumspect about reaching a conclusion, the clinician must plan a treatment program with a greater awareness of the child's possible potential strengths and weaknesses.

Purpose of the Study

The purpose of this study is to investigate the relationship between spontaneous speech and standardized speech and language test scores in children with prenatal exposure to toxic substances and to compare the results of the tests and spontaneous speech samples with those of children tested who were not prenatally exposed. The information from this study should be of use to speech-language pathologists, educators, physicians, and others working with the population of language delayed children who were prenatally exposed to toxic substances.

Hypotheses

It is hypothesized that children who were prenatally exposed to toxic substances will perform significantly more poorly on a spontaneous speech sample than on a standardized speech and language battery. It is additionally hypothesized that children who experienced no intrauterine toxicity will not demonstrate such disparity in their test performance. In particular, it is hypothesized that:

1. Performance on the Developmental Sentence Scoring (DSS) (Lee \& Koenigsknecht, 1974) will correlate more strongly with drug exposure than with the Peabody Picture Vocabulary Test - Revised (PPVT - R), Form M 
(Dunn \& Dunn, 1981), the Expressive One-Word Picture Vocabulary Test (EOWPVT) (Gardner, 1990), and the Sequenced Inventory of Communication Development (SICD), Receptive and Expressive Scales (Hedrick, Prather, \& Tobin, 1984). That is, drug exposure or non-exposure will be a better predictor of spontaneous speech performance than performance on a standardized speech and language battery.

2. The DSS scores will correlate more strongly with drug exposure than with three qualitative variables associated with the child's living situation: socioeconomic status, being in a foster home, or being in a single-parent home.

3. Once the effect of drug exposure is removed, the other tests and the qualitative variables considered will not show a significant correlation with DSS scores.

\section{Definition of Terms}

A variety of terms are used in this research, some of which have been accepted and made popular by the media. Other terms are narrowly defined by their meaning for speech-language pathologists.

1. Abuse and neglect. The definitions of the terms "abuse" and "neglect" have been outlined by the National Committee for Prevention of Child Abuse (Sparks, 1989). These definitions do not focus on the intent of the abusing or neglecting individual; rather they focus on the medical and social aspects as they affect the child. The categories concerning the effect on the child include: physical abuse, sexual abuse, emotional abuse, physical neglect, and emotional neglect. The definition which Congress has legally 
adopted (1974 Federal Child Abuse and Treatment Act -P.L 93-247-and the 1978 amendments. L. 95-266) is as follows:

The physical or mental injury, sexual abuse or exploitation, negligent treatment, or maltreatment of a child under the age of eighteen, by a person who is responsible for the child's welfare under circumstances which indicate the child's health or welfare is harmed or threatened thereby. (p. 54)

Children with developmental delays may be more vulnerable to various forms of abuse and/or neglect than normally developing children (Sparks, 1989). In a study of 101 children injured from abuse, Sparks has shown that $70 \%$ were delayed developmentally or physically prior to the abuse. Children born exposed prenatally to drugs, with a host of disorders, may be particularly at risk

2. High risk or at risk The risk determination, for the purposes of this investigation, were made by California Children's Protective Services social workers or We Care Center social workers who ordered and supervised the child's enrollment in the preschool. The terms "at risk" or "high risk" refer to birth and/or environmental factors which might compromise a child's ability to develop normal gross motor, fine motor, speech and language, personal-social, cognitive and/or adaptive skills.

California Children's Protective Services is a county agency which is a subdivision of the State of California Department of Social Services and the Child Welfare Services department. The We Care Center is a private nonprofit foundation which serves children from birth to age 6 who are at risk for 
developmental and/or behavioral delays. Funding is through state and county grants as well as private contributions.

3. Drugs. Substances which may impair the child's development and are in use either illegally or legally in the United States include: cocaine, crack cocaine, methamphetamines, heroin, methadone, PCP, LSD, alcohol, and marijuana. Other substances which may be toxic to the developing fetus and which are widely used and legally permissible include alcohol, tobacco, and methadone. Alcohol and tobacco, in particular, have been definitively linked to birth defects and developmental disorders. These substances are subject to abuse by users.

a. Cocaine: Cocaine is a tropane alkaloid derived from the leaves of the cocoa plant. Classified as a stimulant drug, it is similar in structure and clinical symptoms to amphetamines. It increases the heart rate and contractibility and blood glucose. It causes alertness, hypervigilance, and the "fight or flight" response. It may be smoked, snorted (used intranasally), or taken intravenously (Bresnahan, Brooks, \& Zuckerman, 1991).

b. Crack cocaine: Crack cocaine is alkaloidal freebase cocaine. It has a rock-like appearance and is smoked in a water pipe. Crack is about $70 \%$ pure cocaine, while the other forms may be $15 \%$ - $60 \%$ pure. Crack may be further diluted by additives, such as non-drug substances or other drugs (Bresnahan, Brooks, \& Zuckerman, 1991).

c. Methamphetamine: Methamphetamines are first cousins of amphetamines, which cause central nervous system excitation, followed by prolonged sleep, extreme fatigue, and vivid dreams. Long term use may cause psychosis and strokes (Dixon, 1989). 
d. Heroin: Heroin is an opiate which is converted to morphine in the body and has a half-life of $\mathbf{3 0}$ minutes. Heroin causes central analgesia and euphoria (Hayford, Epps, \& Dahl-Regis, 1988).

e. Methadone: Methadone is a synthesized morphine compound with a half-life of 20-30 hours. Both heroin and morphine produce feelings of dependence and addiction. (Kaltenbach \& Finnegan, 1989).

f. PCP: PCP is the chemical compound phenylcyclidine. It is also known socially as angel dust. PCP causes decreased reflexes at birth. There is no assurance that PCP is safe for fetal exposure (Gerber, 1990).

g. LSD: LSD is the chemical compound lysergic acid diethylamide. LSD has been shown to cause physical abnormalities in the fetus. There is no assurance that LSD is safe for fetal exposure (Gerber, 1990).

h. Alcohol: Alcohol is a suspected teratogen in that it causes defects in fetal development (Sparks, 1984).

i. Marijuana: There is no assurance that marijuana is safe for fetal exposure. It is not known if it is a teratogen in humans (Sparks, 1984).

4. Expressive language. Expressive skills are a composite of "phoneme or sound production, expressive vocabulary...syntax, and level of transformational sophistication" (Emerick \& Hatten, 1974, p. 92). Expressive language depends on social context for its meaning. Peterson and Marquardt (1990) stated that, "Pragmatics refers to the meaning of words, phrases, and sentences in context" (p. 111).

5. Receptive language. Receptive language is a composite of the "child's understanding of gestures...reactions to intonations, inflections, facial expressions ... comprehension of speech, linguistic decoding involving 
comprehension of vocabulary ... understanding of grammatical systems" (Emerick \& Hatten, 1974, p. 40).

6. Language sample. A language sample represents the child's speech in conversation. It is "a method for making a detailed, readily quantified and scored evaluation of a child's use of standard English grammatical rules from a tape-recorded sample of his spontaneous speech" (Lee \& Koenigsknecht, 1974, p. xix).

Assessment Measures

A large variety of tests have been developed to assess the language abilities of preschool age children. Among these tests are the PPVT-R, the EOWPVT, the SICD, and the DSS. When administered together, these assessment tools constitute a test battery whose results can be used to determine a child's level of performance and appropriateness for therapeutic intervention.

The PPVT- $R$ measures receptive vocabulary, based on standard American English. The test scores provide information on the subject's vocabulary acquisition and are a useful tool in identifying the level of a subject's achievement in this area. The PPVT- $R$ "has enjoyed widespread popularity over the years, because of the importance of vocabulary as a measure of child development, and because the test is easy to administer even to very young, immature children" (Dunn \& Dunn, p. 2). The test also is useful as a screening tool for children to determine if their receptive language performance is advanced, average, or impaired as compared to their peers. 
The PPVT-R is a standardized test designed for persons from age $21 / 2$ to 40 . It is composed of $\mathbf{1 7 5}$ test items arranged in order of increasing difficulty. Each page of the test has four illustrations, and the subject's task is to point to the illustration of the stimulus word which is presented orally by the examiner. This test is not a test of comprehensive intelligence; it is solely a measure of vocabulary.

The EOWPVT measures the quantity and quality of a child's vocabulary. Gardner stated that, "Expressive language, i.e. verbal expression of language, is thought to be a complicated mental process" (p. 1). The test also provides examiners with information about the child's receptive language skills. It is presumed that the child who has difficulty understanding the meaning of words and is deficient in associating words with pictures will also have difficulty naming pictures. The EOWPVT is designed to be administered to children ages 2 years to 12 years. The format is a single illustration per page, with 143 pages of illustrations. It is easy to administer and demands knowledge by the child and the examiner of standard American English.

The SICD is a test designed for children ages 4 months to 48 months. The test is divided into two sections, the Receptive Scale and the Expressive Scale. The authors described the receptive behaviors to be tested as including awareness, discrimination, and understanding skills. Motor responses to sounds and speech are measured in the testing situation, and parental reports of the child's motor responses to sounds and speech in the home environment are also recorded. 
The authors described the expressive skills to be tested as initiating, imitating and responding behaviors. In addition, verbal output and articulation are measured. As in the Receptive Scale, parental reports of behavior in the home environment supplement the child's responses in the testing situation. In both Scales, semantic, syntactic, pragmatic, and perceptual parameters are evaluated.

The SICD has been utilized extensively by speech-language pathologists in hospitals, private clinics, preschool programs, and special education programs. The authors stated that the test's Behavioral and Processing Profiles are useful in planning remediation for the delayed child.

The DSS is a "useful procedure for quantifying the grammatical structure of children's expressive language" (Lively, 1984, p. 154). Lee and Koenigsknecht (1974) require that the language sample include a minimum of 30 different utterances, with 50 as an ideal number, to be culled from a desired 100 separate utterances. Points are given for the following categories: complete sentences, indefinite pronouns and noun modifiers, personal pronouns, main verbs, secondary verbs, negatives, conjunctions, interrogative reversals, and Wh- questions.

Lee and Koenigsknecht (1974) drew upon Brown's (1973) stages of language acquisition and grammatical structure in devising this test. They stated that, "This combination of many syntactic and morphological rules produces a grammatical load which can be measured for every sentence a child speaks" (p. 56). The DSS measures the child's language growth, "in terms of the increasing grammatical load of a child's spontaneous speech in conversation with his speech clinician" (p. 56). 
The DSS is designed for use with young children in the developmental stages of language learning (from ages 2-0 to 6-11). The sample should be tape recorded for later transcription. Appropriate materials, designed to elicit spontaneous speech, should be chosen for use by the child. The examiner may elicit speech through comments or questions if the child is not forthcoming. Lively (1984) notes that the DSS is especially useful in analyzing the children who are at Brown's (1973) Stage II (mean length of utterance 2.25 or beyond). 


\section{CHAPTER 2}

\section{Review of the Literature}

Babies born too early or too small run substantial risks of suffering from a variety of congenital anomalies, illnesses, and infections (Schorr, 1989). Low birthweight babies are common outcomes of maternal drug abuse. But drugs alone can cause congenital anomalies and neurodevelopmental handicaps, even if the child is born at term and is of average height and weight. A serious consequence of both drug exposure and low birthweight in newborns which has a "direct bearing on later outcomes is that many ... grow up with learning disorders and behavior problems" (p. 67). Schorr reported that the rate of learning disabilities may be as high as $40 \%-45 \%$, and that related problems include "poor language development and reading problems, difficulty with abstract concepts, poor impulse control, and attention deficit disorder" (p. 67).

A variety of studies attest to Schorr's (1989) findings and support the general malaise among professionals serving children born exposed to drugs that these children face risks in their development. A number of research reports are presented with a focus on their relevancy to the child's ability to develop both receptive and expressive language skills. The child's neurologic status, as well as emotional well-being will also be highlighted as these factors are thought to contribute to the child's ability to communicate.

Cocaine and its impact on infant behavior are described in this first review. Neuspiel and Hamel (1991) explored the range of effects on brain development, both in the prenatal and postnatal periods. The authors were careful to riention that illicit drug use is common in all social and ethnic 
groups and is particularly prevalent among young adults, including pregnant women. In a study comparing women enrolling for prenatal health care at both private and public health practices in Florida, the authors noted that positive toxicology results varied little between the women in public clinics and private offices.

Neuspiel and Hamel (1991) stated that cocaine easily crosses the placenta and establishes high fetal brain levels, with the concomitant potential for neurotoxicity. Animal studies are cited in describing the increased incidence of eye and skeletal defects, cardiovascular, limb, and genitourinary malformations, decreased birthweight, and increased stillbirths in the cocaine exposed rats. Reflex development may also be delayed, including reaction to painful stimuli. While animal study findings may be difficult to apply directly to humans, they do suggest that the developing human brain has some vulnerability to the drug.

The authors were particularly concerned about low birth weights in infants born of substance abusing mothers. Low weight and decreased head circumference have been associated with microcephaly, delayed cognitive and language development, and later behavioral problems. Chasnoff, Landress, and Barrett (1990) are cited for their study showing increased irritability, tremulousness, and poor motor organization in cocaine exposed infants, in addition to low birth weight.

Cocaine is known to cause fetal hypoxia by decreasing uterine blood flow and impairing oxygen delivery to the fetus. Deficits and delays in development which have been caused by prenatal and perinatal oxygen 
deprivation have been demonstrated in animal studies and documented in humans.

Adding to the effects of cocaine are the problems resulting from prematurity or fetal growth retardation caused by maternal reduced weight gain. Among the factors contributing to the mothers' depressed weight are: the anorexic effects of the drug, a lack of attention to appetite caused by the drug's effects, income diverted to acquisition of the drug rather than food, poverty as a factor in exposure to drugs, ignorance of and/or indifference to nutritional needs during pregnancy, and untreated illness stemming from little or no medical care.

The neurobehavioral effects of cocaine may continue to affect the infant after birth, through exposure by passive inhalation, direct ingestion, or breast feeding. Four infants so exposed were described in this study as having abnormal neurologic signs (seizures, drowsiness, and ataxia). Other infants described had a variety of behaviors, in addition to those already mentioned, including: apnea, irritability, vomiting, diarrhea, hypertension, hyperactivity, and a high pitched cry.

Neuspiel and Hamel (1991) wamed the reader that many prenatal factors may confound or alter the effects of cocaine, including exposure to other illicit substances, as well as to licit drugs. Environmental agents, prenatal care, parental age, infections, gestational age, infant's sex, and birth weight must all be considered when attempting to assess the behavioral outcomes of prenatal exposure. Neglect, abuse, and injuries following birth should not be ignored either. Children born with prenatal exposure to cocaine should be considered at high risk for developmental disorders and 
disabilities. The authors urged that these children be assessed individually, as each case is a composite of many factors affecting the child's potential.

A review of the pharmacology of cocaine is a prelude to a study by Bresnahan, Brooks, and Zuckerman (1991) on the impact of cocaine on infants and mothers following prenatal exposure. Cocaine produces a magnification of the pleasure response, creating heightened sensations of euphoria and power. Spitz and Rosecan (1987) noted that rats continued to press levers to obtain cocaine, even if it caused them to die of an overdose. Cocaine increases heart rate, blood pressure, peripheral muscle contractions, and blood glucose. It also stimulates the "fight or flight" response, causing the alertness and hypervigilance related to this response. Cocaine dependence has an identifiable withdrawal syndrome, which can continue indefinitely. The syndrome is marked by the individual responding to conditioned cues (people, places, and/or objects) which can trigger a relapse at any time. Cocaine, which is used intranasally (snorted), intravenously, or smoked, crosses the placenta and the blood brain barrier. The drug can be detected in urine up to 96 hours after exposure. Recently, screening detection in hair and meconium has been developed.

In the addicted mother, cocaine suppresses the appetite as well as the mother's drive or ability to care for herself. Depression, guilt, and selfloathing are some of the feelings the addicted mother may develop as a result of her inability to stop using the drug. Complications from maternal cocaine use, which impair the developing fetus, can include abruptio placentae, preterm labor and delivery, hemorrhagic lesions in the central nervous system, decreased nutrient transfer, as well as other ill effects mentioned in 
the previous article cited. Since women who use cocaine are likely to use other substances to enhance the drug's effects, such as cigarettes, alcohol, and marijuana, the fetal outcome may be further compromised. The low birthweight and decreased head circumference characteristic of cocaineexposed newborns are compounded by these other factors known to cause poor fetal development.

Fetal anoxia may be related to brain lesions in cocaine-exposed newborns, as cited by Dixon and Bejar (1989). Lesions in the basal ganglia, frontal lobes, and posterior fossa seem to be due to the vasoconstrictor effects of cocaine. The potential therefore arises for cognitive and perceptual-motor impairments, as well as disturbances in affect. There has also been evidence of vision and hearing deficits in cocaine-exposed infants, again as a possible result of vasoconstriction leading to anoxia.

Dixon and Bejar (1989) cited Bresnahan, Brooks, and Zuckerman (1991) who described infant studies of cocaine-exposed newborns who displayed developmental problems on the Brazelton Neonatal Behavioral Assessment Scale. The authors noted that the infant's disorganization is frustrating for the caregiver as well. The quality of the child's environment may be as important to the exposed infant's outcome as the amount of fetal toxic exposure, according to Lifschitz, Wilson, O'Brien-Smith and Desmond (1985), but the highly addictive nature of cocaine works against positive outcomes for those infants who remain with their addicted and/or recovering mother.

Dixon (1989), a recognized expert who studies fetal exposure to toxic substances, cited the increasing incidence of exposed infants born in Southern California. The increases in San Diego, as well as in Los Angeles, she 
attributed largely to consumption of cocaine and methamphetamines. This study provides a table of the clinical consequences of cocaine use in adults, and it is presumed that the fetus is also vulnerable as the drug penetrates the placental barrier through diffusion. Infants prenatally exposed to cocaine may exhibit a variety of skeletal and or skull defects, evidence of hemorrhagic infarction, and transient hypertension. The neonate may have impaired visual processing and alertness and may demonstrate tremulousness and an exaggerated startle reflex. Dixon also cited EEG changes in the frontal central vertex regions, noting that frontal anomalies may later be manifested as learning problems in the school age child. Fine motor disturbances are also evidenced in the infant's first year of life, and visual-motor coordination may be impaired.

The infant exposed to methamphetamines appears less impaired in the first year, according to Dixon (1989). However, while these children may seem to exhibit minor neurologic abnormalities (passivity, poor alertness, lethargy, poor feeding), their outcome may be particularly severe. Examples of disabilities related to methamphetamines include apraxia, dystonia, intention tremor, and hemiparesis developing after a relatively calm neonatal period.

Of particular interest in Dixon's (1989) article is a discussion of two groups of infants compared economically, sociologically, and racially. One group was drug free at birth, while the other tested positive for drug exposure. Using a multiple regression format to analyze all of the factors involved in the perinatal outcomes, Dixon found that "only drug exposure contributed 
statistically significantly and adversely to intrauterine growth and gestational age in both the cocaine- and methamphetamine-exposed groups" (p. 440).

In a study of the development of preschool children of heroin addicted mothers, Wilson, McCreary, Kean, and Baxter (1979) found that these children had disturbances in growth and behavior as a result of fetal exposure to heroin. The children's birth weight and gestational age were diminished, and low height and small head circumference were maintained in early childhood. The heroin-exposed children performed poorer than comparison groups on the McCarthy Scales of Children's Abilities and the Illinois Test of Psycholinguistic Abilities. Once again, the authors pointed out that the difference between children of addicts and comparison groups cannot be attributed to the parent's educational level, income, ethnic group, age, or socioeconomic status. The only factor of significance in contributing to the drug-exposed children's impairment was heroin. The authors stated that heroin alters the child's behavior, perceptual and organization abilities, thereby making the child vulnerable to learning and behavior problems.

Kaltenbach and Finnegan (1989) described a group of studies comparing narcotic-exposed children with non-exposed children from similar socioeconomic backgrounds. One study found that the narcotic-exposed group performed more poorly on various subscales of the McCarthy Scales of Children's Abilities. The subscales included the perceptual, quantitative, and memory sections of the General Cognitive Index.

The authors also mentioned other studies where scores between the two groups were similar, or where the narcotic-exposed group performed higher than expected. The scores may be a reflection of the problem of 
eliminating the many variables which each child brings to the study, rather than a reflection of a particular group's strength. Kaltenbach and Finnegan (1989) also suggested that higher scores in the narcotic-exposed group may be related to the fact that the children's mothers were willing participants in longitudinal studies, perhaps reflecting a life style that would lead to their child's strong performance on a developmental battery.

The life style of the majority of drug dependent women differs considerably from that of non-drug dependent women, however. In addition to the chemical effects of the drug on the mother and fetus, the women often suffer from depression, anxiety, poor nutrition, and a chaotic life style. Physical and sexual abuse may be factors in their past or present history, factors which further compromise their ability to be competent caregivers to their infants. The drug-exposed infant is at risk for exposure to an adverse environment, where the child's developmental progress may not be a concern to the parent.

Lewis (1991) presented information which suggests that the number of drug abusing Americans is increasing and is paralleled by an increasing number of births of exposed newborns. In a recent study of 36 hospitals across the United States, $11 \%$ of the newborns tested positive for illicit drugs. The newborns exhibited irritability, increased tremulousness and startle reflexes, poor feeding abilities, poor sleeping patterns, and diarrhea. The infants also had increased muscle tone and abnormal suck and swallow patterns. The potential effect on speech caused by these oral motor disorders has not yet been demonstrated, but may be a serious cause for concern. Lewis also cited a growing body of information which describes drug-exposed toddlers as 
having particular risks for developmental delays. The delays include social, emotional, behavioral, and language problems and may be factors leading to the child's potential risk for future academic and social failure.

While specific developmental delays were not addressed in the next short research synopsis, Kobori, Fierriero, and Golabi (1989) once again reminded the readers of the potent teratogenicity of cocaine. In a study of 11 infants born with major central nervous system and/or craniofacial anomalies, 6 of the 11 mothers used cocaine only, and 5 of the 11 used cocaine with other illicit drugs throughout their pregnancies. The disorders included several brain anomalies, such as hypoplastic corpus callosum with unilateral parietal lobe cleft, intraparenchymal hemorrhage, and unilateral hemispheric infarctions. Facial disorders included cleft lip, cleft palate, and Pierre Robin anomaly. Serious neurodevelopmental disabilities of a global nature were seen in the 7 infants who survived, where it is presumed that speech and language development would also be compromised.

Fulroth, Phillips, and Durand (1989) studied 86 infants who were born to mothers with a positive history of either cocaine or cocaine and heroin abuse. Testing of the infants shortly after birth revealed that 20 were negative for heroin or cocaine despite their mothers admitting to cocaine use during pregnancy. Of concern in the group of 66 infants testing positive were factors reported in the maternal history which may have been inaccurate. While the mothers of exposed infants admitted to using either heroin or cocaine, they may have been reluctant to describe their related activities, such as ingestion of other street drugs, alcohol, or tobacco. As cocaine is known to suppress the 
appetite, poor maternal nutrition affecting fetal growth is also likely to be underreported, if reported at all.

Cocaine is implicated in growth retardation, microcephaly, and prematurity in infants. Fetal growth is inhibited because cocaine has a vasoconstrictive effect on the placenta, which results in reduced fetal blood flow and hypoxia. Use of cocaine in the third trimester is most likely the cause of growth retardation, as the fetus grows rapidly during this phase. Cocaine also impacts the central nervous system by altering the dopamine, serotonin, and norepinephrine receptors and affects the release of neurotransmitters. While cocaine causes seizures and produces hyperactivity in the infant, the consequences of the abnormal reactions are not well understood.

The authors did not hesitate to warn, however, of the potential for long term developmental problems in exposed infants. The concern that changes in the brain will impair the child's cognitive and language development, as well as fine and gross motor abilities, was implied.

Gerber (1990) cautioned that it may be difficult, if not impossible, to determine the effect of a drug on a developing fetus. Since many addicted mothers engage in poly-drug abuse, consume inadequate diets, and eschew medical care, the process of explaining cause and effect can be intricate and complex However, the sheer numbers of affected children with definable physical anomalies, disabilities, and development disorders are causing researchers to reach conclusions which separate the effects of one drug from another. 
For example, heroin- or methadone-exposed infants display definite drug withdrawal signs at birth and are hyperirritable for several months. These children may also be hyperactive, at least until age 3 . The disruption to learning caused by hyperactivity and its often associated phenomenon, attention deficit disorder, can be significant.

Other drug effects on the unborn child are equally concerning for their potential to impair the child's learning abilities, stated Gerber (1990). For example, marijuana-exposed infants exhibit behavior similar to the heroinexposed, including narcotic withdrawal. These babies have diminished responsiveness to light and a high incidence of tremors.

Infants prenatally exposed to cocaine show signs of prenatal oxygen deprivation. Gerber (1990) cited Chasnoff, Lewis, and Squires (1987) who documented a normal, non-exposed birth, where an infant suffering signs of oxygen deprivation was admitted to a hospital emergency room at age 2 weeks. The infant had cocaine intoxication from breast milk. Oxygen deprivation can cause strokes in the fetus, as well, by affecting circulation. Any part of the body can be affected, with atrophy resulting from the insult.

The drug PCP also crosses the placenta to reach the fetus. Babies have decreased reflexes at birth and poor attention skills. LSD has been shown to cause limb and eye deformities.

Methamphetamines and barbiturates taken in excess by the pregnant women can produce serious problems in the infant and developing child. Methamphetamine exposure is linked to childhood emotional disturbances, while barbiturates have been associated with long term behavioral problems. The prenatal death of brain cells is thought to be the causal factor. 
Alcohol related defects have been well documented in literature (Dorris, 1989) and the media. Two conditions, Fetal Alcohol Syndrome (FAS) and Fetal Alcohol Effect (FAE), may result. Failures in growth, dysmorphism, physical abnormalities, and mental retardation are among the possible outcomes to children as a result of alcohol consumption by their mothers. It has not yet been definitively proven if the father's alcohol intake and/or drug abuse prior to conception contributes to fetal anomalies and/or childhood disabilities.

Smoking during pregnancy has been directly linked to low birth weight in babies. Low birth weight is a common denominator for learning disabilities, communication disorders, and mental retardation. Smoking during pregnancy has also been documented to cause minimal brain dysfunction, an impairment that can be the basis for emotional, behavioral, and learning deficits.

Fried and Watkinson (1990) examined the separate effects of prenatal exposure to marijuana, as well as to cigarettes or alcohol, in 130 36-month and 130 48-month old children. The authors were attempting to ascertain whether there were negative relationships between the use of these substances and the children's verbal and memory skills, by comparing these children's test results with those of a group of 50 non-exposed children.

Decreases in performance for those children prenatally exposed to cigarettes and alcohol were found at both ages in a variety of activities using the McCarthy Scales of Children's Abilities, the Reynell Developmental Language Scales, and the PPVT - R Differences were statistically significant in the verbal component of the McCarthy, with children of heavy smokers 
scoring even more poorly than the others on the test of verbal skills. The children exposed to marijuana demonstrated overall diminished cognitive performance both at the 36- and 48-month old stages. Again, the verbal component of the McCarthy was the most strikingly delayed and the most statistically significant. At age 48 months, the children of heavy marijuana users had particular deficits associated with memory and verbal skills on these measures.

Fried and Watkinson (1990) provided important commentary for their study: first, prenatal marijuana exposure contributes to cognitive and verbal deficits in young children; secondly, the long-term effects of marijuana exposure are subtle and may not be fully manifested prior to age 4 ; thirdly, the population which Fried and Watkinson assessed was not deemed high-risk That is, the subjects' life-styles and nutrition were thought to be comparatively healthy. The authors cautioned that their findings, when generalized to other populations, could possibly be conservative.

The staff of the Drugs and Drug Abuse Education Newsletter (1990) cited statistics which estimate that $30 \%$ of drug-exposed infants do not leave the hospital with their mother, but instead are placed with foster families. The remaining 70\% return home with their biological mother. There are varying estimates of the number of infants who remain hospitalized for treatment of disorders secondary to intrauterine toxicity, particularly prematurity and/or low birth weight. This figure is as high as $19 \%$ in some reports.

But the early childhood of the drug-exposed infant, according to the National Association for Perinatal Addiction Research and Education, may 
be extremely traumatic. Those in foster homes may be subject to multiple placements, as caretakers weary of the extremely challenging behavior of these children, particularly those who are hypersensitive, hypervigilant, and exhibit difficulties with feeding and sleeping.

The situation in the mother's home may be even more concerning. The home may be disorganized and chaotic if drug abuse has not ceased. Mothers and children may experience physical abuse and neglect. The mother may be unable to provide a nurturing, safe, and stimulating environment for her child as a result of her drug-seeking behavior. Many drug-addicted women live in poverty and are hampered by lack of education and the social skills needed to take advantage of community resources available to them. The staff of the Drugs and Drug Abuse Education Newsletter (1991) cited these behavioral consequences of drug exposure (both maternal and fetal) as contributing factors in the child's long term learning and development. The cost to society for medical care, foster care, educational services, and social support systems to both mother and child is staggering. For a physically or neurologically damaged drug-exposed child in Florida, the present cost of education alone through age 18 is approximately $\$ 750,000$. The cost to the individual child, who may suffer physical, behavioral, language, and learning difficulties, is alas, incalculable.

In another study of the damaging effects of drugs on the fetus, Oro and Dixon (1987) compared groups of exposed newborns. The groups contained 13 infants exposed to cocaine, 28 exposed to methamphetamines, 9 exposed to cocaine or methamphetamine and another narcotic, 5 exposed to cocaine and methamphetamine, $1 \%$ exposed to heroin, and 32 exposed to methadone and 
heroin. The comparison group of 45 infants was drug-free. Mothers in all groups were matched by age, extent of prenatal care, and ethnicity. All of the drug-exposed infants had reduced intrauterine growth as compared to the non-exposed infants, with correspondingly decreased birth weight, length, and head circumference. The exposed infants all were characterized by abnormal sleeping and feeding patterns, tremors, and hypertonia.

Disorganized rooting and sucking were also documented in the exposed groups.

The authors noted that illicit drug use by the mother may indicate that she is at high risk for medical, social, and psychological problems. Multiple regression analyses ruled out the association of these factors, however, with the observable effects of the drug exposure on the infant remaining.

Additionally concerning was the fact that infants with combined exposure to cocaine, or methamphetamine with another narcotic, fared more poorly than those in all other groups. All of the exposed children studied had the potential for childhood behavioral and cognitive disturbances, stated the authors, which could be attributed to maternal ingestion of one or more drug on one or more occasion during pregnancy.

Substance abusing mothers and their exposed infants present unique problems. The mother's life is characterized by disorganization both within and outside of the home. She may have difficulty following simple instructions, providing basic care to herself and her child, and protecting herself (and her child) from abuse stemming from the drug culture. The authors noted that the mother may have difficulties with attention and perception, may be forgetful, and may have difficulty staying awake. The 
child is at risk for abuse, neglect, and developmental delays. The child's cognitive and language skills may be slow to emerge or may be permanently limited due to the child's inability to attend to critical stimuli.

In another study (Hayford, Epps, \& Dahl-Regis, 1988) of children born to heroin-addicted and methadone-addicted mothers, a variety of medical problems in the infants were noted at birth. The authors cited Wilson, McCreary, Kean, and Baxter (1979) who reported that 30 exposed neonates experienced birth trauma, including respiratory distress.

In yet another group mentioned by the authors, the neonates experienced withdrawal and had symptoms involving the central nervous and gastrointestinal systems. Symptoms of irritability lasted for more than 3 months. Toddlers of the addicted mothers were found to be easily distracted and with brief attention spans. While they were voluble and extremely energetic, the children's fine motor skills were immature and, in particular, the researchers found perceptual, cognitive, and speech differences in this age group. When 70 children, ages 3-6 years, born of addicted mothers were compared with 70 children of the same ages born of non-addicted mothers, differences in development persisted. The exposed group scored lower on the Stanford-Binet Intelligence Scale. They also had difficulties learning new tasks and adapting to new situations. The authors warned that matemal drug addiction and the consequences for newborns and children will become major health issues in the United States. They also stated that developmental delays in these children will further compromise their performance and behavior in the future. 
While Kelly, Walsh, and Thompson (1991) confined their research to neonates, their discussion of the drug-exposed fetus' future home environment is worth examining If the child remains with his/her mother, the mother's continued use of illicit drugs places her and her family at increased risk for health, social, and psychological problems. Among the risk factors are: limited or absent prenatal care, homelessness, single parenting. poly-drug abuse, criminal activity to obtain drugs or money for drugs (i.e. theft, prostitution), and the potential to be abused. These women are also prone to depression and feelings of worthlessness and guilt for their seemingly desperate sttuations. In a study by Griffin (1988), ten percent of drug using mothers were intravenous users, a factor which raises the risk for their acquiring human immunodeficieny virus (HIV) and then passing it on to their fetus.

In this and several other research reports, the neonates' developmental delays noted at birth were not equated with any environmental antagonists, but were linked solely to the effects of the drugs on the developing fetus. However, public attention to the broad spectrum of negative influences on a drug-exposed child's development must be increased if changes are to be made which will give each child a fair start in life.

While the child born with FAS or FAE may exhibit identifiable physical anomalies (such as short stature and facial dysmorphism), the most disabling sequella of prenatal exposure to alcohol is mental retardation. In a study by Shaywitz, Cohen, and Shaywitz (1980), 85\% of 126 FAS identified children had tested IQs below 70 . 
The authors followed a group of exposed children to measure their growth, anatomic anomalies, central nervous system irregularities, intellectual functioning and school related skills and behavior. Most of the children were hyperactive and required medication to decrease their distractibility and to increase their short attention span. All of the children were receiving special education services by the third grade.

While alcohol is legally available to all (including pregnant women) over an age determined by each state, the effect of this substance on the fetus is potentially harmful. Alcohol effects are mentioned here because illicit drug consumption is often coincidental with alcohol ingestion and alcohol abuse. Children who are mentally retarded as a result of FAS exhibit speech and language deficits in one or many areas and may have reduced pragmatic abilities as well.

Sparks (1984b) listed the effects of alcohol exposure to fetuses, citing various studies which measure symptoms and behaviors. She noted in this article the paucity of information on and investigations of speech and language development in FAS. A case was described (Iosub, Fuctis, Bingel, \& Gromisch, 1981) which told of an FAS child with extremely poor speech prior to repair of his cleft palate, who then spoke fairly well by age 4 .

Unfortunately, the description by Iosub et al. was incomplete and the child's speech and language skills were not measured against those of his peers. Spark's implication and concern were that communication deficits could be among the possible serious consequences of maternal alcohol abuse.

A study by Hanson (1976) was cited in Sparks' book, Birth Defects and Speech-Language Disorders (1984a), in which 41 cases of FAS children were 
described. There was no evidence that any of these children's delayed mental abilities improved over time. Even with adequate nutrition, nurturing homes, and appropriate mental and emotional stimulation, the children's IQs remained the same, and environmentally positive factors had no effect.

Sparks (1984a) also described studies of speech and language in drug-exposed children. In a report by Wilson, Desmond, and Verniad (1973), the authors found that children of heroin addicted mothers had scores similar to normal children on the receptive and expressive subtest measures of the Illinois Test of Psycholinguistic Abilities. These same exposed children did poorly on the tests which measure organization.

In a case study of a 21-month old child whose mother had taken LSD while pregnant, Sparks (1984a) noted that the child had a diagnosis of developmental aphasia. The child (a girl) had apparently not vocalized before age 20 months and didn't babble until after age two years. This child had serious expressive and receptive language delays and, at age 7 , she was diagnosed as trainable mentally impaired with speech and language, cognitive, and processing disorders.

In a study by Davis (GAO, 1990) at New York's Harlem Hospital Center, a group of drug-exposed preschool age children, including one-third born prematurely and one-third born with microcephaly, language delays were noted in $90 \%$ of this group. This article revealed that most of the children also had delays in their fine and gross motor skills. More than $30 \%$ of the drug-exposed children had a diagnosis of hyperactivity and short attention span. Additionally disturbing was that significantly disproportionate rates of cerebral palsy and autism were found in the Harlem Hospital population. 
The author recommended a multi-disciplinary team approach to providing the delayed child with special education services.

In a study comparing 18 drug-exposed 18 -month old children with a high-risk group of toddlers who were not exposed, differences were found (Howard, Beckwith, Rodning \& Kropenske, 1989). The drug exposure group was strikingly deficient in self-organization, self-initiation, and followthrough with assistance. The drug-exposed children's representational play was significantly less frequent and less varied than that of the comparison group. The drug-exposed children had difficulty sustaining play, developing fantasy play, or engaging in exploration of the environment. Most often, their play consisted of scattering objects, batting objects, or simply picking them up and then putting them down. Howard et al. stated that cognitive development is compromised by prenatal drug exposure and that even when the child is situated in a stable, nurturing foster home, the effects of the drugs cannot be eliminated.

Sowder and Burt (1980) sought to learn about the young children of heroin addicts through developmental testing. They compared 34 exposed 3-6 year olds with 34 non-exposed 3-6 year olds, all with similar socioeconomic backgrounds. The tests used included the Draw-a-Person IQ Test, the PPVT-R, and the Stanford-Binet Vocabulary Subtest.

As a group, the exposed children did not perform as well as the comparison children. For example, 23 of the exposed group scored below average for their age, while only one-third of the non-exposed group scored below average. 
Of particular interest was the authors' finding that, while the children did demonstrate recognition of words on the PPVT-R, many of the 3 - 4 year old exposed children could not respond on the Stanford-Binet Vocabulary Subtest. They would either remain silent or would echo the stimulus word. According to Sowder and Burt (1980), "They simply seemed unable to convey their idea of what a word means using age-appropriate language" (p. 40).

The older exposed children were more vocal and tended to respond to the subtest, but their responses were inappropriate and did not pertain to the stimulus. Additionally, all of the exposed children tended to be concrete in their expressive production. They tended to describe what they saw rather than to draw conclusions in an abstract-conceptual manner.

In another study of exposed infants (Ting Keller, \& Finnigan, 1978), 49 children between the ages of 6 and 41 months were evaluated for gross and fine motor skills, adaptive abilities, personal-social behavior, and language skills. These children were compared on each parameter with a non-exposed group of 50 similar age children.

Except for one child in the exposed group whose Developmental Quotient (based on Gesell's schedule) was extremely low, there was no significant difference between the groups in gross motor, fine motor, adaptive, or personal-social behavior. The researchers noted that the exposed group demonstrated disorganized behavior during the evaluation as well as inadequate cooperation with the testing personnel, but that the scores did not reflect these behaviors. On the other hand, language behavior in both groups was poor, with the exposed groups performance significantly lower. The researchers also cautioned that test scores in children of addicts participating 
in a study may be higher than those of exposed children in the general population.

Meyerson (1991) pointed out that there are a limited number of studies specifically in the area of speech and language development relating to the exposed child. What is known about these children is that they may have "uncoordinated sucking and swallowing, lower developmental scores, attention deficit, poor interaction with peers, distractibility, and abnormal play patterns ... and ... a risk for auditory system deficits" (p. 7). Prenatal exposure to alcohol and/or illegal drugs can produce a wide variety of obvious symptoms, minor "soft" neurologic signs, or isolated and specific deficits. Other problems which could delay or impair speech and language development include processing and memory deficits, hyperactivity, hypersensitivity to noise, dysarthria, voice, and fluency disorders. Poly-drug or single drug exposure over a long portion of a pregnancy or even a one time exposure could account for receptive, expressive, or cognitive delays.

But documentation of specific areas of speech and language deficits is scarce. In order to plan remediation for exposed infants and children, specific delays must be explored and identified. Meyerson (1991) suggested that expressive language may be an area of concern when she stated, "intelligible verbal output must be the primary goal" (p. 7). She encouraged therapy which would work toward this end, while decreasing the focus on drill for enhancement of receptive language, vocabulary, syntax, and articulation. Meyerson was concerned that the child might become frustrated by too many demands and that basic communication by the child must be achieved before other language goals are advanced. 
This final study was chosen to highlight concerns about the two populations chosen for this investigation. Fox, Long, and Langlois (1988) examined speech and language disabilities in abused and neglected children, comparing 30 identified children with 10 non-abused children. While none of those in the abused/neglected group were identified as prenatally exposed to drugs, the likelihood that one or more were exposed exists. The study group were all in foster care and therefore had similar living situations to the children in this investigation.

All of the children in Fox, Long, and Langlois' (1988) study were between the ages of 3 and 8 . They were tested with a battery, including the PPVT- $R$, the Miller-Yoder Language Comprehension Test, and the Token Test for Children. The results of the study showed that not only did those children who were abused and neglected do poorly on language comprehension tasks, but that they had poorer expressive language than their matched controls The authors were mindful that it is difficult to draw conclusions about the causes of language delay in abused and neglected children, precisely because there are a myriad of complex known and unknown factors contributing to the child's ability to learn. This study is valuable, nevertheless, because all of the children chosen for this investigation may be at risk for expressive language delays due to factors in their environment. Therefore, the test scores of the non-exposed group which will be presented in Chapter IV may not be comparable to the test scores of a non-exposed group of children of similar socioeconomic and ethnic background, who were not subject to abuse and neglect. 


\section{CHAPTER 3}

\section{Methodology}

\section{Subjects}

Twenty preschoolers between the ages of $\mathbf{3 0}$ months and $\mathbf{4 2}$ months were chosen from a group of $\mathbf{4 0}$ children who were volunteered for the investigation by their parent(s) and/or legal guardian(s). Seven females and 13 males were assessed on two measures of vocabulary (one receptive recognition and the other expressive identification), one combined receptive and expressive test of language development, and one measure of spontaneous speech structure and complexity. The experimental population, as well as the control group, were selected following receipt of parental or guardian permission. All of the children were attending the We Care Center day treatment program, a private non-profit program supported by state, county, and private funding. The children were enrolled in this program as a consequence of their identification as high risk children. The children came to the preschool for remediation of developmental and/or social-emotional delays attributed to their high risk situations and histories. They were identified prior to their enrollment by social service workers on behalf of California Children's Protective Services. Eight of the 20 children were in foster homes. Others were previously in foster homes but were reunited with their biological parent or parents, and still others had been with their biological parent(s) since birth.

The male/female ratio for the drug-exposed group of 10 children was 5 males / 5 females. The male/female ratio for the non drug-exposed group was 8 males $/ 2$ females. The ethnic composition of the drug-exposed group was 4 
Black, 1 Hispanic, and 5 Caucasian children. The ethnic composition of the non drug-exposed group was 2 Black, 4 Hispanic, and 4 Caucasian children. All of the children were presently residing, or had resided for at least 6 months previously, with Caucasian parents (or guardians). All of the children and their families spoke standard English as their primary language. Also, all of the children fit Brown's (1973) criteria for Stage II (mean length of utterance -2.25 or beyond). None of the children involved in the study was bilingual nor did any child speak non-standard English.

The families' socioeconomic status was determined by the social workers, based on family income, prior to the child's admission to the We Care Center. The families' incomes were determined to be representative of lower or middle segments of society, based on income reported before taxes for all family members. Income sources such as work, public assistance, and unemployment insurance were tallied for this purpose

All of the children in the study resided in Concord, California or in three adjacent towns (Antioch, Oakley, or Pittsburg). These communities are similar in their cultural, ethnic, and economic compositions. All of the communities support some light industry, and all have similar ratios of single family dwellings to multiple family dwellings.

The factor which separated the two groups of children was evidence of drug exposure at birth. All of the children, according to birth records, were subject to toxicology studies at birth, as they were born predominantly in county hospitals where drug screening of infants has become routine. Ten children identified positively for drugs at birth were assigned experimental group status, while the non-exposed children were in the control group. 


\section{Materials}

The following tests were administered: the PPVT-R, Form $M$, the EOWPVT, the SICD, Receptive and Expressive Scales, and the DSS. The tests were administered individually to each of the 20 children. The total testing time for each subject was between 1 hour and 15 minutes and 1 hour and 30 minutes. Testing for each child was accomplished in one session.

\section{Procedures}

Following receipt of parental or guardian permission for the child's participation in this research (see Appendixes A and B), each child was tested individually by the examiner. The testing room was approximately $8^{\prime} \times 10^{\prime}$, with one door to the adjacent hallway leading to the child's regular classroom. This office had a viewing mirror through which observers could watch the proceedings. The room was furnished with a desk, chair, toy and book shelf, wall cabinets, child-size table and two child-size chairs. Parents / guardians were invited to observe the testing but none did so.

During testing the child and examiner sat at the child-size table and the office was quiet, well-lit, and devoid of overstimulating decorations or toys. The subjects were cooperative and received stickers at the end of their session, as a reward for their participation and as a notification to their parent/ guardian that the testing had taken place.

The first test administered, the PPVT- $R$, required a non-verbal response which involved finger pointing at a named stimulus picture. When asked to, "Show me the...," the child was to point to the named picture out of four possible choices per page. 
The second test administered was the EOWPVT. The instructions required that the child name the sole picture which appeared on each test page, following the examiner's prompt of, "What is this?"

The third test administered, the SICD, both receptive and expressive portions, required receptive, expressive, and manipulative responses. The receptive portion was given before the expressive portion. Stimulus pictures and objects, as well as verbal directions, were utilized to elicit responses for both portions. The SICD provides the examiner with a standardized test kit which includes children's toys, picture cards, and hearing acuity devices. Beyond object identification and responding to a variety of simple and complex questions, the child is offered the opportunity to make comparisons, solve problems, and use abstract reasoning skills. Pragmatic skills are measured as well.

The final test administered, the DSS, required the child to speak spontaneously while engaging in a typical childhood activity, in as natural a setting as possible. A Fisher-Price doll house and school bus, with accompanying dolls, fumiture, doll toys, and doll-size cars were set on the table in front of the child. The examiner made a few brief comments about the activity, following Weismer's (1991) recommendations: "Let's play with the dollhouse and bus." "Let me help you open the house." "Where's the baby?" With no more encouragement from the examiner than an occasional, "What's that?" "I see that." "Where is the ... ?" "What is that ... doing?", or "Uh huh," the children all chattered to themselves and to the examiner for 15-30 minutes. Their vocalizations were recorded using a Sanyo portable cassette tape recorder (Model M115), and each child's speech sample was later 
transcribed for data compilation. More utterances than the 30-50 recommended by Lee were recorded, and all children were recorded on one occasion only. The final sample was culled, for each child, from the greatest number of complete sentences.

\section{Statistical Measures:}

The data were assembled for twenty children, equally divided between drug-exposed and non drug-exposed. The means and standard deviations of the five tests and the ages for the entire sample are shown in Table 2. The means of the PPVT-R, the EOWPVT, the SICD-Receptive Scale, and SICDExpressive Scale test scores in an age-equivalent manner were near 35 and the standard deviations around 5 to 6 .

A regression analysis was used to investigate the proportion of variance in DSS scores accounted for by several different variables. Exposure to drugs, parent's marital status, socioeconomic status, and home environment (foster home or not) were all independent variables entered into the analysis using dummy coding. The remaining independent variables, all continuous, were the four other administered speech tests. The qualitative statistics are presented in Table 1. Using the data in Table 2, the correlation matrix shown in Table 3 was constructed. The partial correlations, with the effect of drug-exposure removed, were calculated and the resulting matrix is also shown in Table 3.

The significance of the correlations was evaluated using $t$-tests. In addition, the regression was expressed in terms of an analysis of variance (ANOVA). The first variable eliminated was the one that was most strongly 
correlated with the dependent variable, the DSS. The partial correlations were used to analyze the remaining dependences for statistical significance. 


\section{CHAPTER 4}

Results and Discussion

The purposes of this study were (a) to investigate the relationship between spontaneous speech and standardized speech and language test scores in children with prenatal exposure to toxic substances and (b) to compare the results of the tests and spontaneous speech samples with those of children who were not prenatally exposed.

Of the 20 children chosen for the study, 10 had been exposed to drugs in utero and 10 had not. It was possible to investigate the importance of three aspects of the familial situation as well because 9 of the children (of whom 4 were drug-exposed) came from single-parent families, 8 (of whom 5 were drug-exposed) lived in foster homes, and 7 (of whom 5 were drug-exposed) were from lower rather than middle socioeconomic status. The characteristics of the $\mathbf{2 0}$ children who were tested are shown in Table 1. Their individual scores on the different tests are shown in Table 2. A statistical analysis was done to measure the effects on DSS scores of drug exposure, socioeconomic status, having a single parent, or living in a foster home. The degree to which performance on the DSS could be predicted from the other tests was also examined.

Table 1 provides information about the backgrounds of the children, including their birthdates, ethnicity, and parameters that might influence their performance on tests. These include socioeconomic status (as determined by a social worker when the child was admitted to the program, on the basis of family income), whether the child lives with a foster parent, whether the child is from a single parent family, the length of the child's 
Table 1

Characteristics of Children Tested

\begin{tabular}{|c|c|c|c|c|c|c|c|c|c|c|}
\hline * & $\begin{array}{l}\text { age in } \\
\text { months }\end{array}$ & $\operatorname{sex}$ & ettinicity & $\begin{array}{l}\text { drug- } \\
\text { exposed }\end{array}$ & \begin{tabular}{|l|} 
single \\
parent
\end{tabular} & $\begin{array}{l}\text { foster } \\
\text { parent }\end{array}$ & $\begin{array}{c}\text { socio- } \\
\text { economic } \\
\text { class }\end{array}$ & \begin{tabular}{|c|} 
months \\
of school
\end{tabular} & $\begin{array}{l}\text { working } \\
\text { parents }\end{array}$ & $\begin{array}{c}\text { Mother's } \\
\text { age at } \\
\text { child's birth }\end{array}$ \\
\hline & & & & & & & & & & \\
\hline 1 & 36 & $\mathbf{F}$ & B & $y$ & $n$ & $y$ & middle & 12 & 2 & ? \\
\hline 2 & 42 & $\mathrm{M}$ & $H$ & $y$ & $y$ & $n$ & low & 16 & 0 & 20 \\
\hline 3 & 33 & $\mathbf{F}$ & C & $y$ & $n$ & $n$ & middle & 11 & 1 & 31 \\
\hline 4 & 37 & $M$ & B & $y$ & $n$ & $y$ & middle & 4 & 1 & 16 \\
\hline 5 & 35 & $\mathbf{F}$ & C & $y$ & $n$ & $y$ & middle & 13 & 1 & 18 \\
\hline 6 & 39 & $M$ & B & $y$ & n & $y$ & low & 19 & 2 & $?$ \\
\hline 7 & 40 & $M$ & C & $y$ & $y$ & $n$ & low & 12 & 0 & 19 \\
\hline 8 & 34 & $M$ & C & $y$ & $n$ & $y$ & low & 24 & 1 & $?$ \\
\hline$g$ & 35 & $\mathbf{F}$ & $\mathbf{B}$ & $y$ & $y$ & $n$ & low & 13 & 0 & 22 \\
\hline 10 & 34 & $F$ & C & $y$ & $y$ & $n$ & low & 16 & 요 & 38 \\
\hline 11 & 38 & $M$ & $H$ & $n$ & $n$ & $y$ & middle & 10 & 2 & $?$ \\
\hline 12 & 33 & $M$ & B & $n$ & $n$ & $y$ & middle & 16 & 2 & 26 \\
\hline 13 & 42 & M & C & $n$ & $n$ & $n$ & low & 7 & 0 & 21 \\
\hline 14 & 42 & $F$ & H & $n$ & $n$ & $y$ & middle & 15 & 2 & $?$ \\
\hline 15 & 40 & $M$ & C & $n$ & $y$ & $n$ & low & 3 & 0 & 25 \\
\hline 16 & 42 & $M$ & C & $n$ & $y$ & $n$ & low & 20 & 0 & 33 \\
\hline 17 & 37 & $M$ & B & $n$ & $y$ & $n$ & low & 3 & 0 & 16 \\
\hline 18 & 33 & $F$ & $H$ & $n$ & $n$ & $n$ & low & 21 & 0 & 23 \\
\hline 19 & 37 & $M$ & $\mathrm{H}$ & $n$ & $y$ & $n$ & low & 16 & 0 & 17 \\
\hline 20 & 40 & $M$ & C & $n$ & $y$ & $n$ & low & 12 & 01 & 19 \\
\hline
\end{tabular}


Table 2

Individual Scores on Different Tests

Drug-exposed Group

child number CA PPVT-R EOWPVT SKCDR SICDE DSS

\begin{tabular}{lllllll}
1 & 36 & 32 & 30 & 32 & 36 & 1.00 \\
2 & 42 & 30 & 34 & 36 & 36 & 2.96 \\
4 & 33 & 25 & 31 & 28 & 32 & 0.36 \\
5 & 37 & 30 & 31 & 32 & 36 & 1.04 \\
6 & 35 & 30 & 32 & 36 & 32 & 0.84 \\
7 & 39 & 39 & 33 & 40 & 40 & 3.60 \\
8 & 40 & 37 & 34 & 40 & 40 & 2.10 \\
9 & 34 & 32 & 28 & 32 & 32 & 1.60 \\
10 & 35 & 31 & 34 & 32 & 32 & 3.10 \\
\hline & 34 & 31 & 31 & 28 & 28 & 0.88
\end{tabular}

$\begin{array}{lllllll}\text { Mean } & 36.50 & 31.70 & 31.80 & 33.70 & 32.50 & 1.75\end{array}$

S.D.

$\begin{array}{llllll}2.95 & 3.89 & 1.99 & 4.40 & 5.42 & 1.13\end{array}$


Table 2

Individual Scores on Different Tests

Non Drug-Exposed Group

child number CA PPVT-R EOWPVT SICDA SICD-E DSS

$\begin{array}{lllllll}11 & 38 & 40 & 39 & 36 & 40 & 7.40 \\ 12 & 33 & 45 & 51 & 36 & 36 & 8.40 \\ 13 & 42 & 44 & 44 & 44 & 48 & 6.30 \\ 14 & 42 & 37 & 38 & 40 & 40 & 6.70 \\ 15 & 40 & 40 & 41 & 40 & 44 & 7.50 \\ 16 & 42 & 48 & 42 & 46 & 44 & 5.80 \\ 17 & 37 & 45 & 40 & 40 & 36 & 5.90 \\ 18 & 33 & 33 & 33 & 36 & 32 & 6.30 \\ 19 & 37 & 45 & 40 & 40 & 40 & 7.80 \\ 20 & 40 & 31 & 35 & 32 & 32 & 7.40\end{array}$

$\begin{array}{lllllll}\text { Mean } & 38.40 & 38.30 & 38.60 & 37.50 & 37.30 & 6.95\end{array}$

$\begin{array}{lllllll}\text { S. D. } & 3.44 & 6.15 & 6.24 & 5.02 & 5.85 & 0.87\end{array}$

Totals for both Drug-Exposed and Non-drug-exposed

$\begin{array}{lllllll}\text { Mean } & 35.84 & 35.00 & 35.20 & 35.60 & 34.90 & 4.35 \\ \text { S.D. } & 7.98 & 6.04 & 5.70 & 4.99 & 6.02 & 2.84\end{array}$

CA is age in months. DSS is given as raw score.

All other scores are age-equivalant in months. 
attendance in a school program, the number of parents working and the age of the mother at the birth of her child. This study was limited to the consideration of drug-exposure, socioeconomic status, living in a foster home, and having a single parent as possible factors in spontaneous speech performance. A larger study might address the other variables listed in Table 1. Table 2 shows the scores the children received on four tests, the PPVT-R, the EOWPVT, the SICD-Receptive Scale and the SICD-Expressive Scale, and the DSS. These data are shown as well in Figures 1 - 16. The visual display reinforces the impression of the data in the Tables: Drug-exposure leads to poor performance on the DSS and poor performance on the DSS correlates more strongly with drug exposure than with any other variable. This qualitative observation is made quantitative below.

This study supports the hypotheses that: (a) Children who were prenatally exposed to toxic substances will perform significantly more poorly on a spontaneous speech sample than on a standardized speech and language battery and, (b) children who experienced no intrauterine toxicity will not demonstrate such disparity in their test performance. By calculating the means and standard deviations of the test scores of each group (exposed and non-exposed), it was shown that on the standardized speech and language batteries, there was an approximately one standard deviation difference between the means of the two groups. On the spontaneous speech sample, there was a difference of 5.20 in the means of the two groups while the standard deviation was only 1.13 within the drug-exposed group and 0.87 in the non-exposed group. The exposed children performed more poorly in each instance. 
Additionally, the following hypotheses were supported:

1. Performance on the DSS will correlate more strongly with drug exposure than with the PPVT - R, Form M, the EOWPVT, and SICD, Receptive and Expressive Scales. The correlations between the DSS and the standard speech and language battery are given in Table 3, which shows the full correlation matrix for the variables considered in the study. The DSS raw score was used as the dependent variable, $y$. The independent variables were taken to be the child's age in months (x1), the PPVT-R age-equivalent score in months $(x 2)$ the EOWPVT age-equivalent score in months $(x 3)$ the SICDReceptive Scale age-equivalent score in months $(x 4)$, the SICD-Expressive Scale age-equivalent score in months $(x 5)$ and three qualitative variables, coded as dummy variables (Marascuilo \& Levin, 1983). The variable $(x 6)$ had the value 1 for children with a single parent and the value 0 otherwise. The variable $(x 7)$ had the value 1 for children in foster homes and 0 otherwise. The variable $(x 8)$ had the value 1 for lower socioeconomic status and 0 for middle socioeconomic status. The variable $(x 9)$ had the value 1 for drugexposed children and 0 otherwise.

As shown in the final column of Table 3, the DSS correlated more strongly with drug exposure than with any of the standardized speech and language tests. Table 3 shows that the PPVT-R and EOWPVT scores correlate positively with the DSS. The SICD-Receptive Scale and SICD-Expressive Scale scores also correlate positively with DSS, though not as strongly as do PPVT-R and EOWPVT. None of the four correlates as strongly with DSS as does drug exposure. 


\section{Table 3}

Correlation Matrix for Variables Considered in the Study

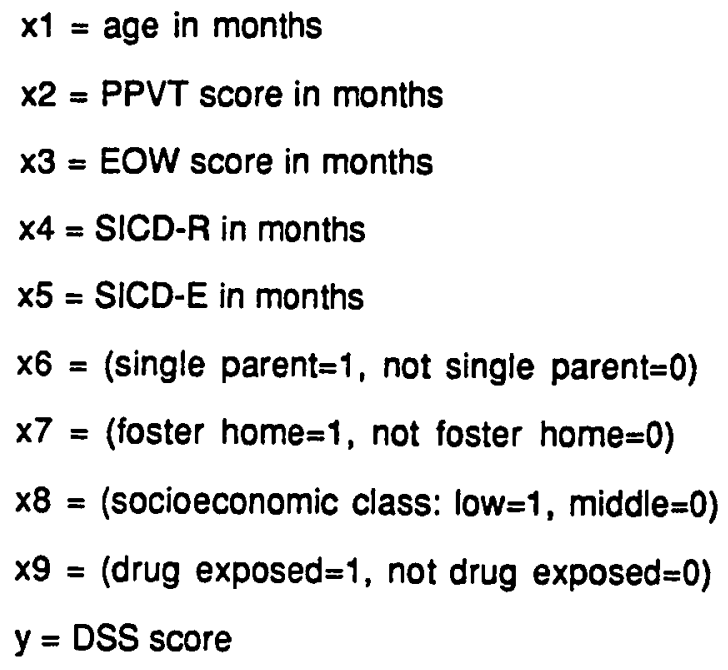

$\begin{array}{llrrrrrrrrr} & \times 1 & \times 2 & \times 3 & \times 4 & \times 5 & \times 6 & \times 7 & \times 8 & \times 9 & y \\ \times 1 & 1.000 & .455 & .309 & .680 & .725 & .397 & -.179 & .268 & -.298 & .332 \\ \times 2 & & 1.000 & .807 & .711 & .751 & .035 & .087 & .107 & -.560 & .611 \\ \times 3 & & & 1.000 & .558 & .639 & -.029 & .007 & -.106 & -.612 & .657 \\ \times 4 & & & & 1.000 & .770 & .193 & -.143 & .306 & -.391 & .387 \\ \times 5 & & & & 1.000 & .084 & -.021 & .023 & -. .409 & .421 \\ \times 6 & & & & & & 1.000 & -.667 & .599 & -.204 & .204 \\ \times 7 & & & & & & & -1.000 & -.685 & .204 & -.155 \\ \times 8 & & & & & & & & 1.000 & -.105 & .178 \\ \times 9 & & & & & & & & & 1.000 & -.939\end{array}$


2. The DSS scores will correlate more strongly with drug exposure than with the three qualitative variables associated with the child's living situation: socioeconomic status, being in a foster home, or being in a singleparent home. This is also shown in the final column of Table 3.

Multiple regression analysis was performed to determine the contribution of the different factors to the DSS scores. Table 3 shows that the strongest correlation of $y$ with any other variable was with (x9), with $r=-.939$. The significance of this correlation can be determined using a $t$-test. From the data we find that $t=11.6$ for $d f=18$, which has a significance of $p<0005$. Put directly, prenatal drug exposure showed a negative correlation with spontaneous speech as measured by the DSS, a correlation very unlikely to have been a chance occurrence.

While the correlation between drug exposure and DSS score is significant, none of the correlations of single parents $(r=.204, d f=18, t=.88)$, foster homes $(r=-.155, d f=18, t=.67)$, or socioeconomic class $(r=.178, d f=18$, $t=.73)$ with DSS is statistically significant. This supports the hypothesis: Spontaneous speech, which is measured by the DSS, is more correlated with in utero exposure to drugs than with the three other qualitative variables investigated. This would suggest drug exposure in utero affects the immature nervous system in such a way as to interfere with normal language development. Specifically, the effect is evident for spontaneous expressive language and less apparent in skills tested by a standardized speech and language battery. 
3. Once the effect of drug exposure is removed, the other tests and the qualitative variables considered will not show a significant correlation with DSS scores. The remaining influence of the other variables is found by calculating the partial correlation of $y$ with them once the effect of $(x 9)$ is removed (Marascuilo \& Levin, 1983). The matrix of all the partial correlations with the influence of $(\times 9)$ removed is shown in Table 4 . The largest of the partial correlation of the DSS score, $y$, is with $(x 3)$ and has the value $r=.304$. This gives an $F(1,17)=1.73$, and thus a $t$ statistic, with the value 1.32 for $d f=17$. This is not significant since it is below the cut-off even for $p=.10$. Thus the only variable having a significant correlation with DSS scores is prenatal drug exposure. The statistical analyses are displayed in an ANOVA in Table 5.

The discrepancy between scores on spontaneous speech samples and scores on standardized tests in the drug-exposed population is most concerning; it suggests deficiencies not only in the exposed child's communication repertoire, but also in the standardized test scores' applications. Among the factors that may contribute to this discrepancy are the following:

1. The standardized test batteries test many skills learned by rote, which are not easily transferrable to conversational speech.

2. The standardized test batteries measure performance based on imitation, repetition, and naming. Conversational speech relies on the child's ability to synthesize this material into comprehensible discourse. 


\section{Table 4}

\section{Partial Correlation Matrix with Influence of Drug Exposure Removed}

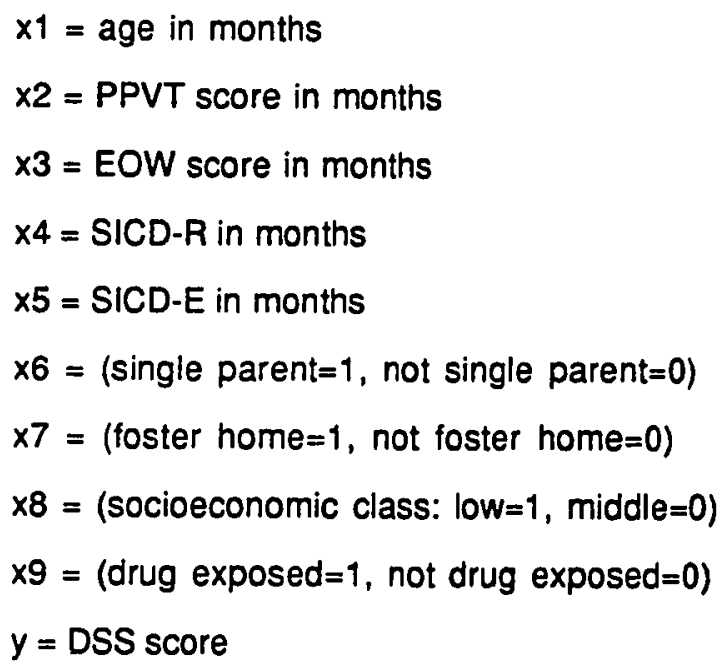

$\begin{array}{rrrrrrrrrr} & \times 1 & \times 2 & \times 3 & \times 4 & \times 5 & \times 6 & \times 7 & \times 8 & y \\ \times 1 & 1.000 & .351 & .167 & .641 & .692 & .360 & -.127 & .250 & .160 \\ \times 2 & & 1.000 & .708 & .645 & .691 & -.098 & .248 & .058 & .297 \\ \times 3 & & & 1.000 & .438 & .539 & -.199 & .171 & -.216 & .304 \\ \times 4 & & & & 1.000 & .727 & .126 & -.070 & .290 & .063 \\ \times 5 & & & & & 1.000 & .000 & .070 & -.022 & .118 \\ \times 6 & & & & & & 1.000 & -.652 & .593 & .038 \\ \times 7 & & & & & & & 1.000 & -.681 & .108 \\ \times 8 & & & & & . & & & 1.000 & .232\end{array}$


Table 5

Analysis of Variance (ANOVA)

First Step: $(x 9)=$ drug exposure

$\begin{array}{lcrrr}\text { Source } & \begin{array}{c}\text { Degrees of } \\ \text { freedom }\end{array} & \text { Sum of squares } & \text { Mean square } & F \\ \text { Regression on }(x 9) & 1 & 135.12 & 135.12 & 134.18 \\ \text { Residual } & 18 & 18.13 & 1.01 & \\ \text { Total } & 19 & 153.25 & & \end{array}$

Second Step: $(x 3)=$ EOWPVT

$\begin{array}{lcrrr}\text { Source } & \begin{array}{c}\text { Degrees of } \\ \text { ireedom }\end{array} & \text { Sum of squares Mean square } & F \\ \text { Regression on }(\times 9) & 1 & 135.12 & 135.12 & \\ \text { Regression on }(\times 3) & 1 & 1.68 & 1.68 & 1.73 \\ \text { Residual } & 17 & 16.45 & 0.97 & \\ \text { Total } & 19 & 153.25 & & \end{array}$


3. The standardized tests measure isolated skills, such as identification of objects by function and gerund responses to "wh" questions. These skills form only a small part of a child's repertoire for spontaneous speech.

4. The standardized tests may be lacking an unknown skill measure which could explain the discrepancy.

5. The spontaneous speech sample measures, on the surface, syntactic, grammatic, and semantic structure. However, a deeper level, which is not well understood and which may not be measurable with presently available tools, involves the recall and synthesis of words and abstract concepts into meaningful speech. There is no scoring procedure for this process either on standardized tests or on language samples.

6. The brevity of the speech sample precludes, perhaps, accurate representation of a child's expressive abilities.

7. Cultural and ethnic factors, as well as second language exposure, may effect a child's performance on different tests within a battery.

8. Exposed children may be less adept at recalling vocabulary for spontaneous speech. Delay in vocabulary acquisition and/or recall may be neurologically based.

The drug-exposed child is at risk for social and academic difficulties, if not failure, if his or her spontaneous conversational speech is deficient. The child who suffers communication deficits is greatly disadvantaged in not being able to express in detail needs, desires, and feelings. Life is confusing in its complexity for young children and may be particularly chaotic for the drugexposed child, who possibly lacks a stable, nurturing home and consistently available parent or guardian. The inability to express herself or himself can 
further undermine the drug-exposed child's fragile existence and contribute to learning and attention difficulties, as well as to the erosion of self esteem. 
Figure 1. Performance of drug-exposed and non-exposed children on the DSS and the PPVT-R.

DSS vs. PPVT $-R$

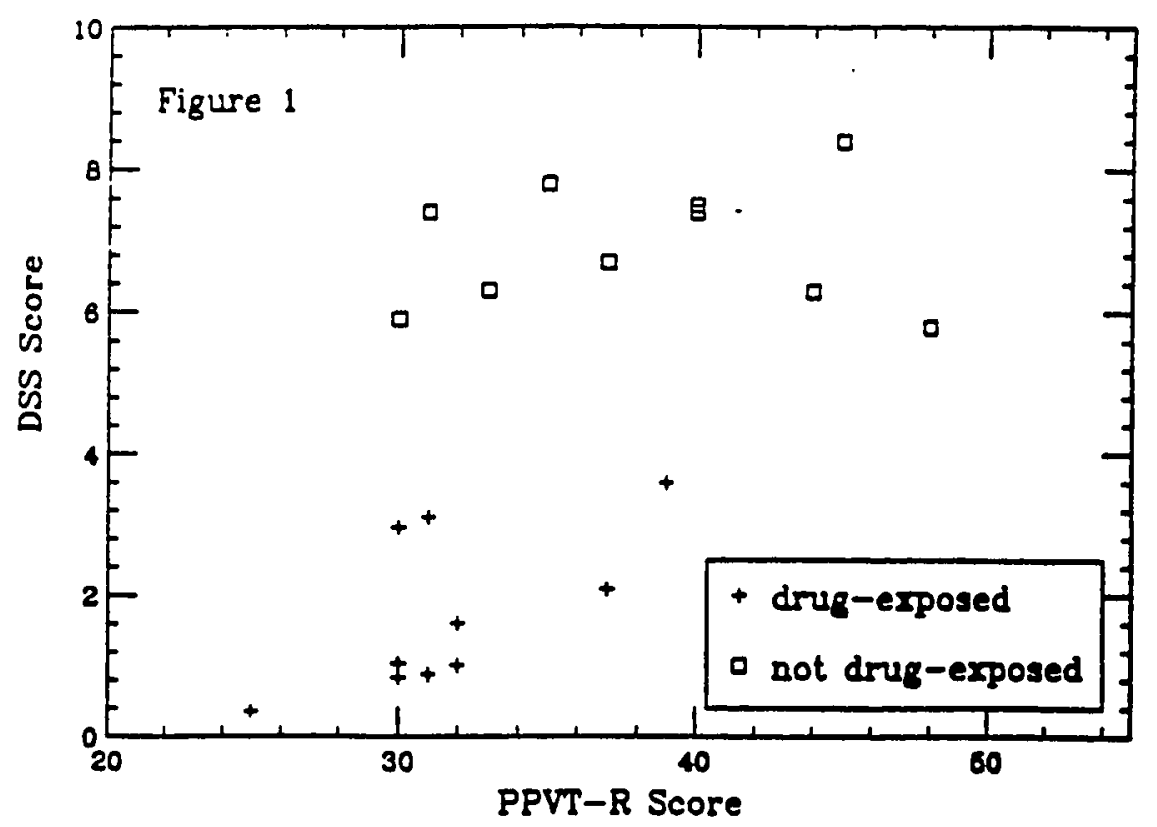

Figure 2. Performance of drug-exposed and non-exposed children on the DSS and EOWPVT.

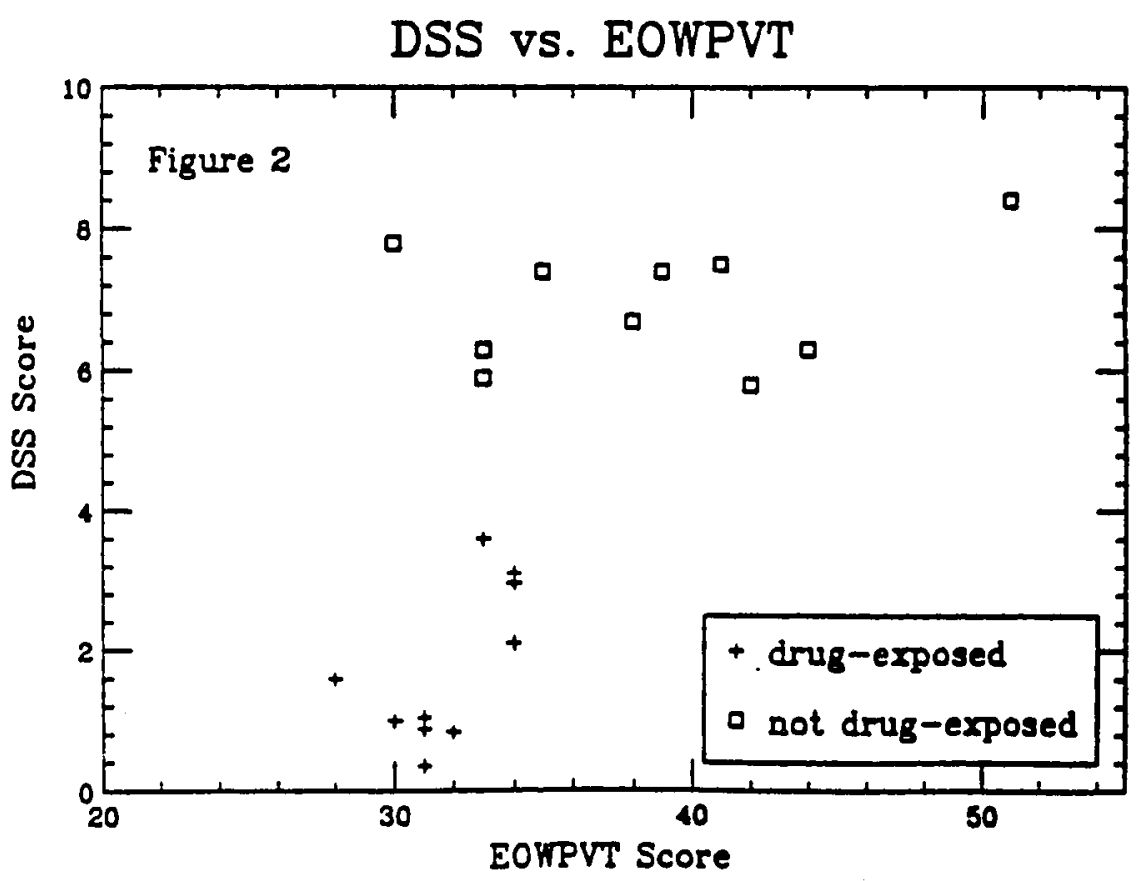


Figure 3. Performance of drug-exposed and non-exposed children on the DSS and the SICD - Receptive Scale.

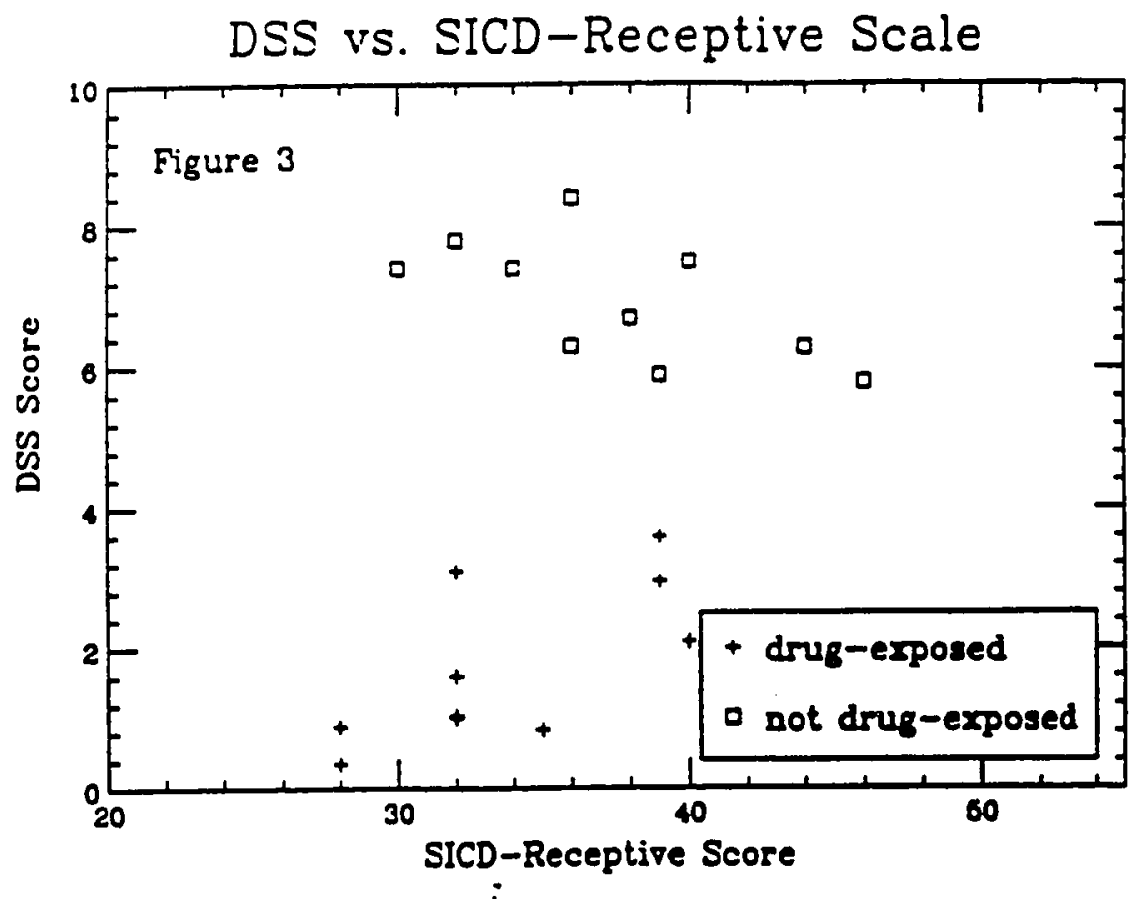

Figure 4. Performance of drug-exposed and non-exposed children on the DSS and the SICD - Expressive Scale.

DSS vs. SICD-Expressive Scale

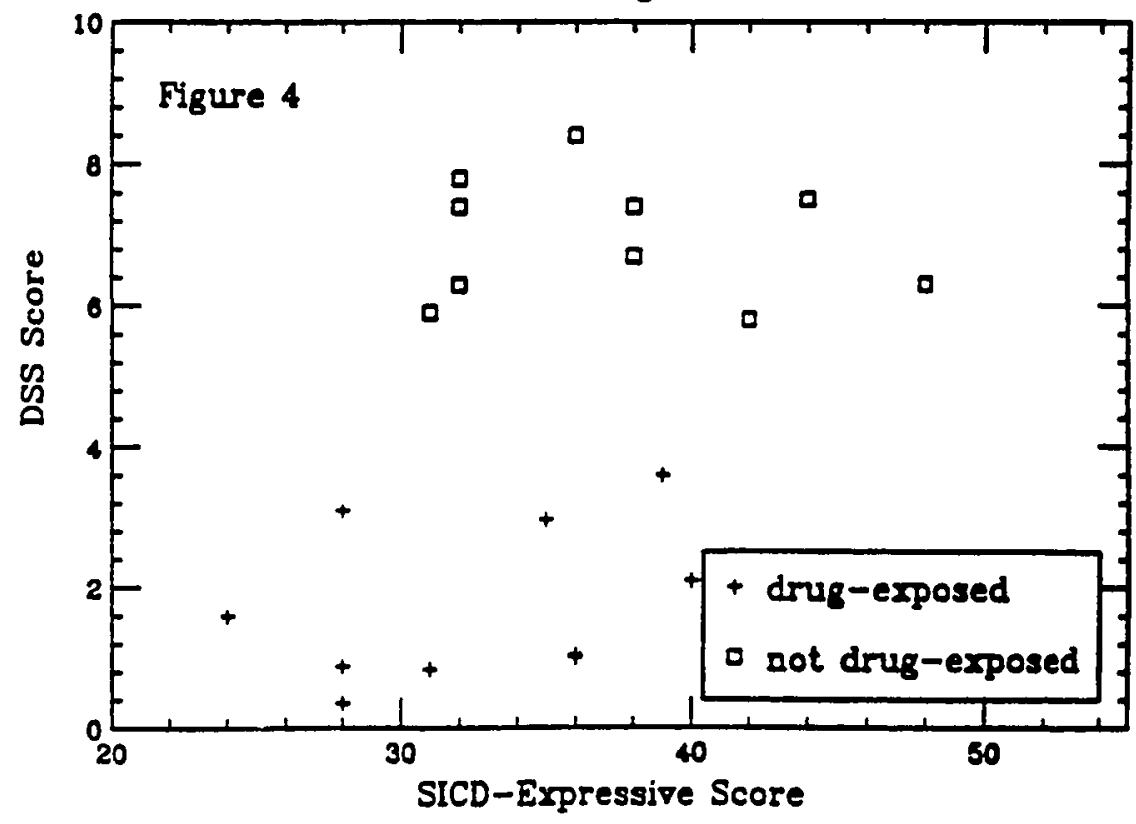


Figure 5. Performance of children from single or non-single parent homes on the DSS and the PPVT-R.

DSS vs. PPVT $-R$

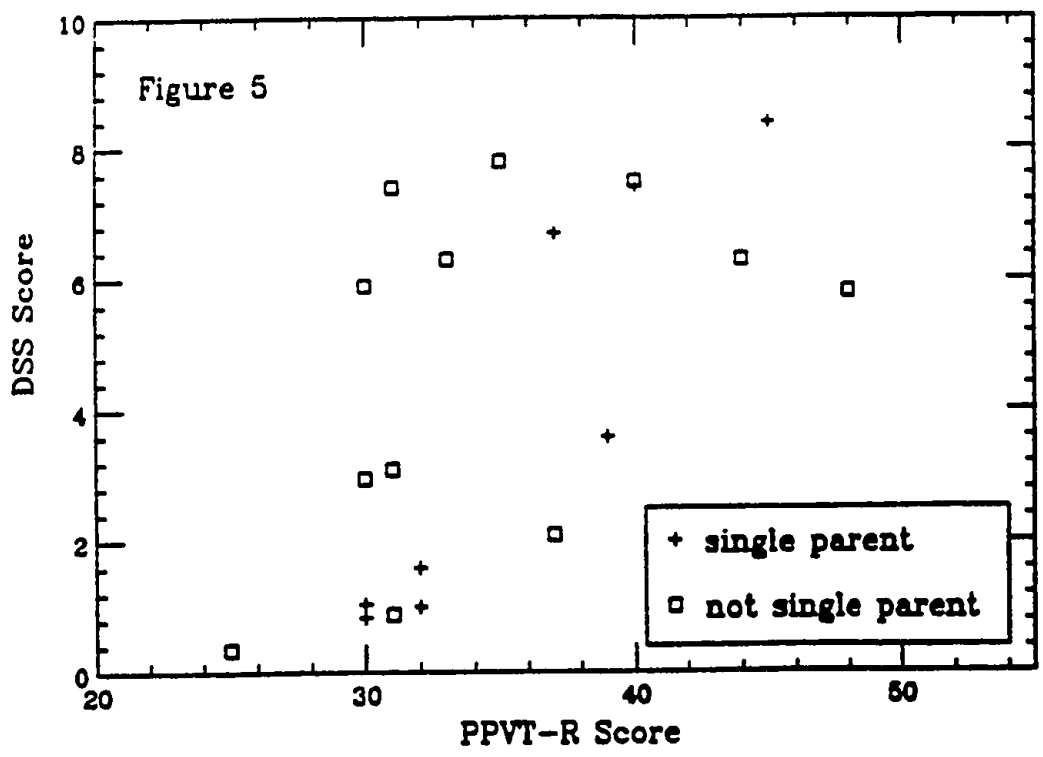

Figure 6. Performance of children from single or non-single parent homes on the DSS and the EOWPVT.

DSS vs. EOWPVT

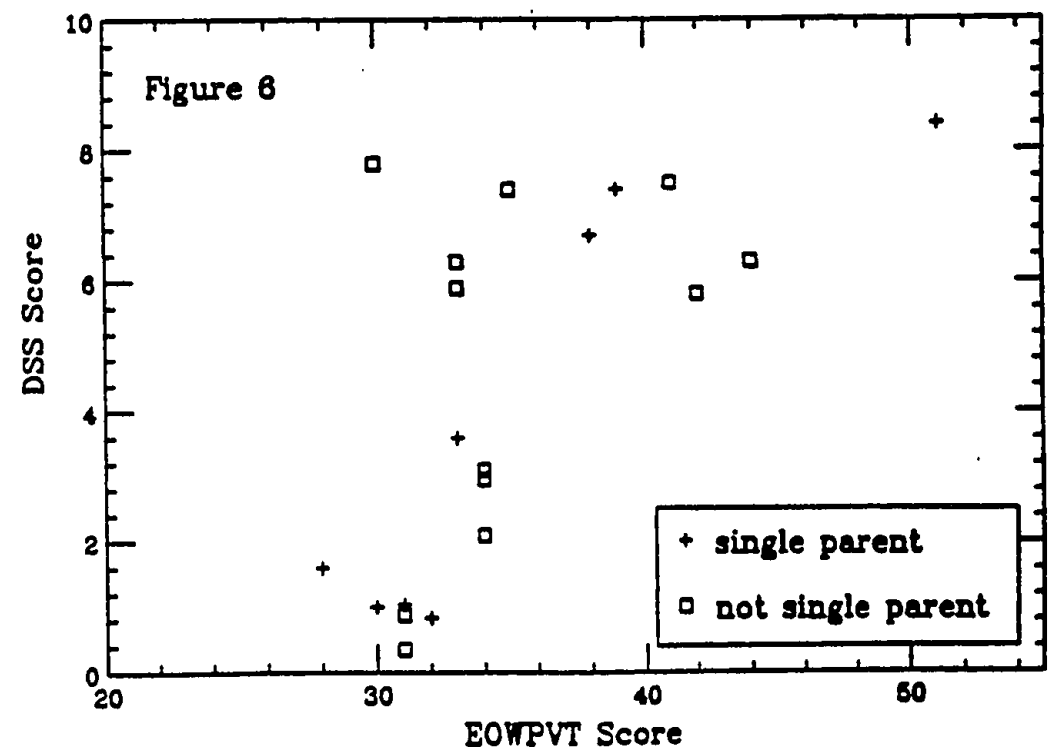


Figure 7. Performance of children from single or non-single parent homes on the DSS and the SICD - Receptive Scale.

DSS vs. SICD-Receptive Scale

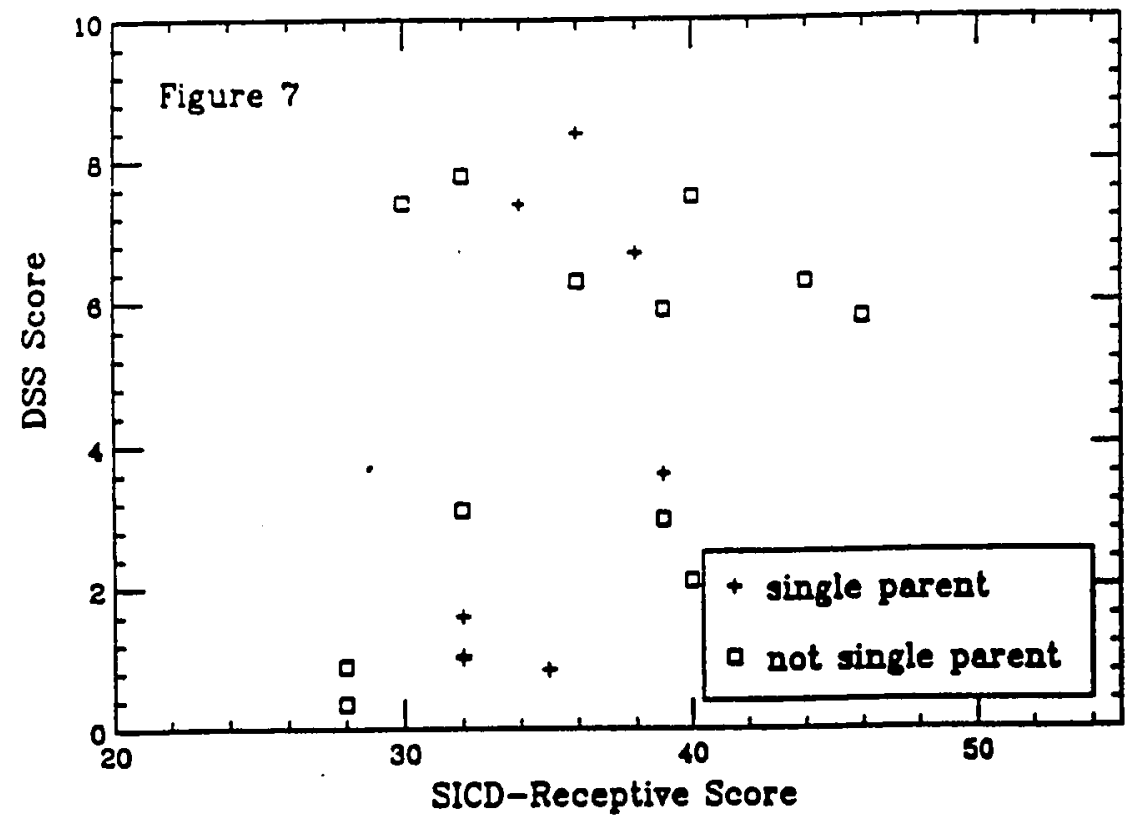

Figure 8. Performance of children from single and non-single parent homes on the DSS and the SICD - Expressive Scale.

DSS vs. SICD-Expressive Scale

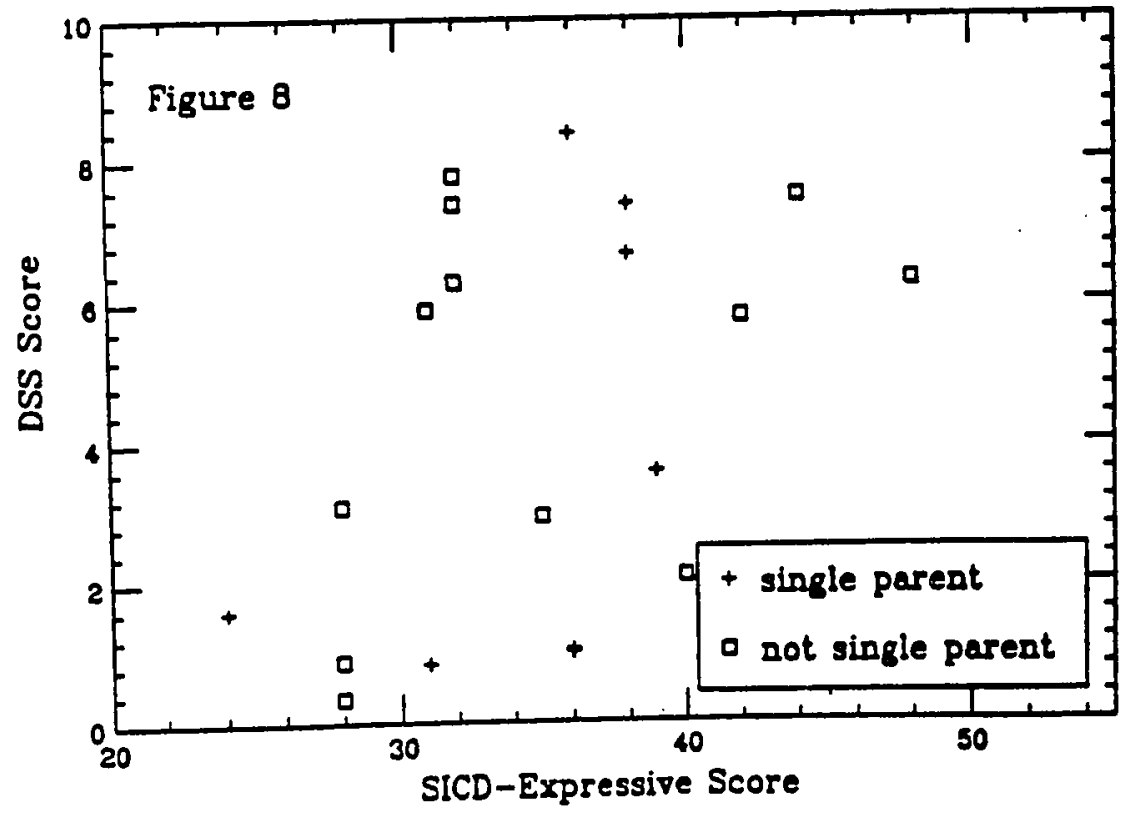


Figure 9. Performance of children from foster and non-foster homes on the DSS and the PPVT.R

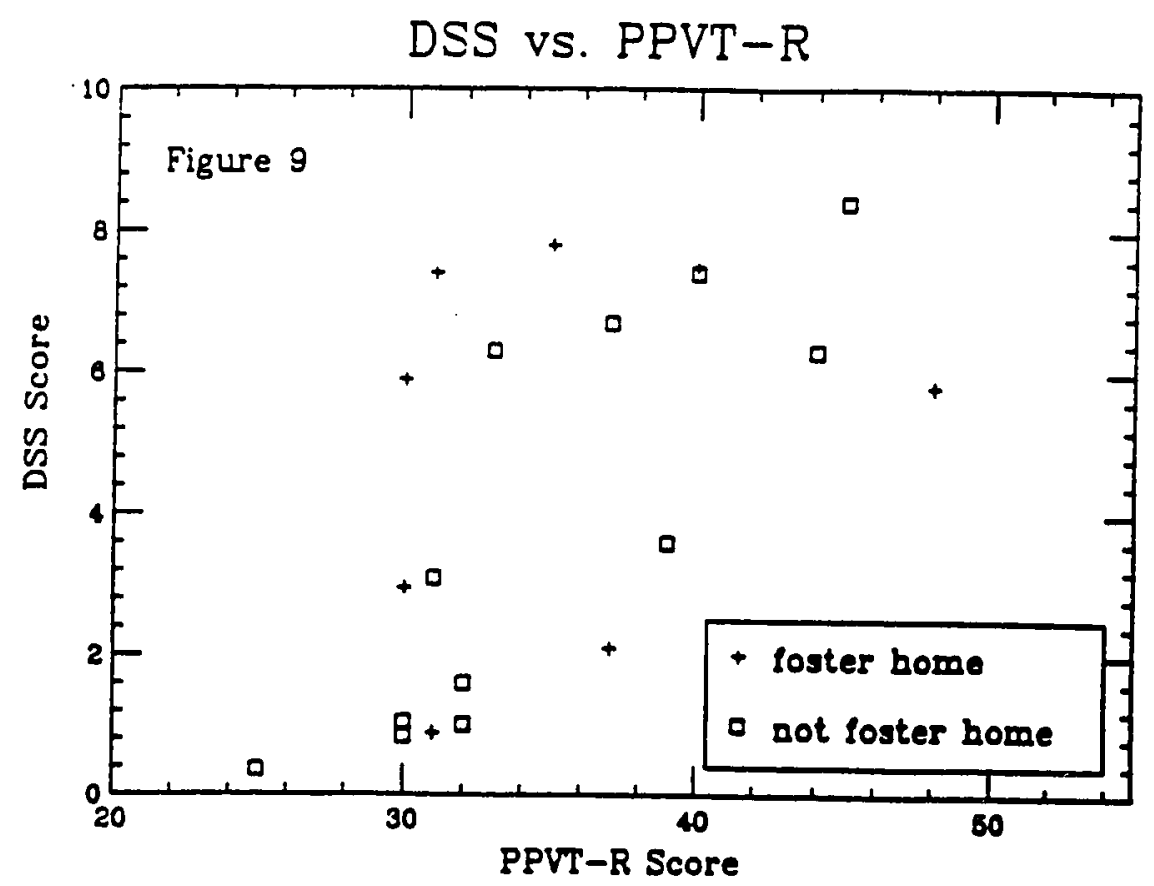

Figure 10. Performance of children from foster and non-foster homes on the DSS and the EOWPVT.

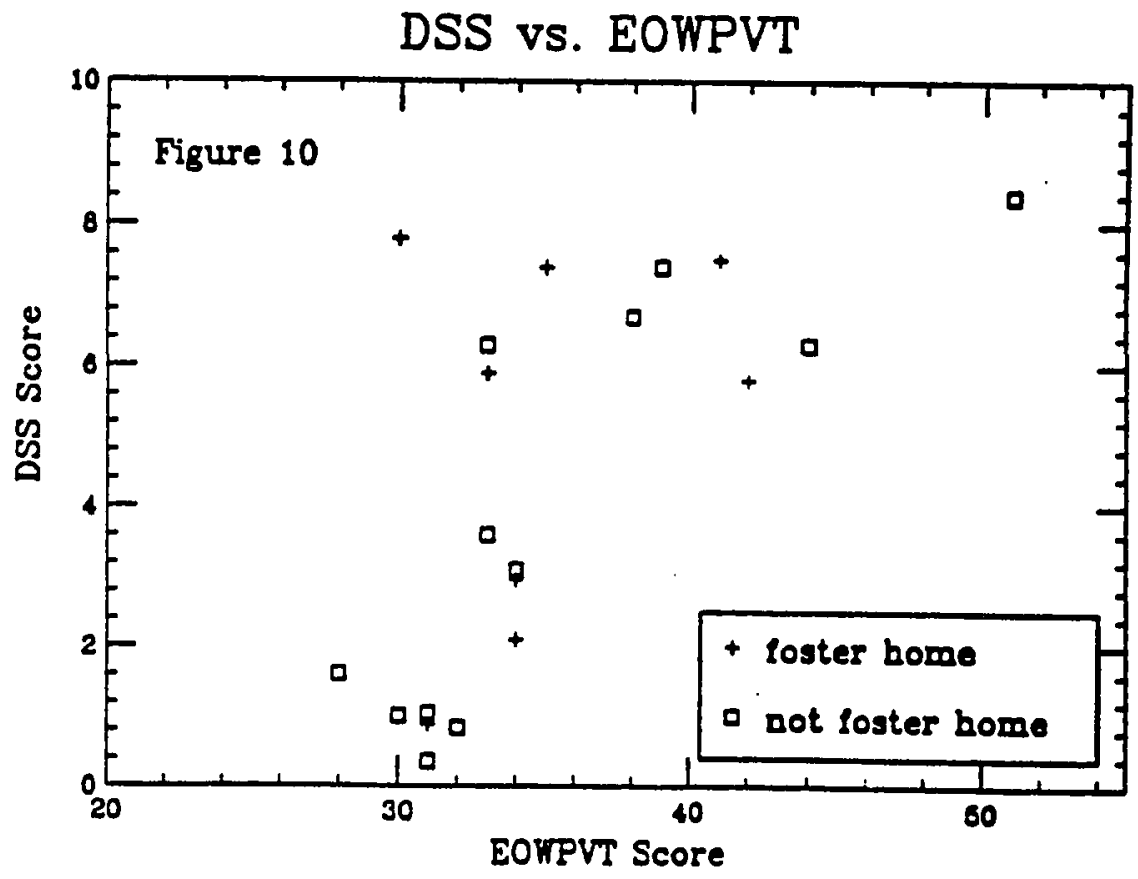


Figure 11. Performance of children from foster and non-foster homes on the DSS and the SICD - Receptive Scale.

DSS vs. SICD-Receptive Scale

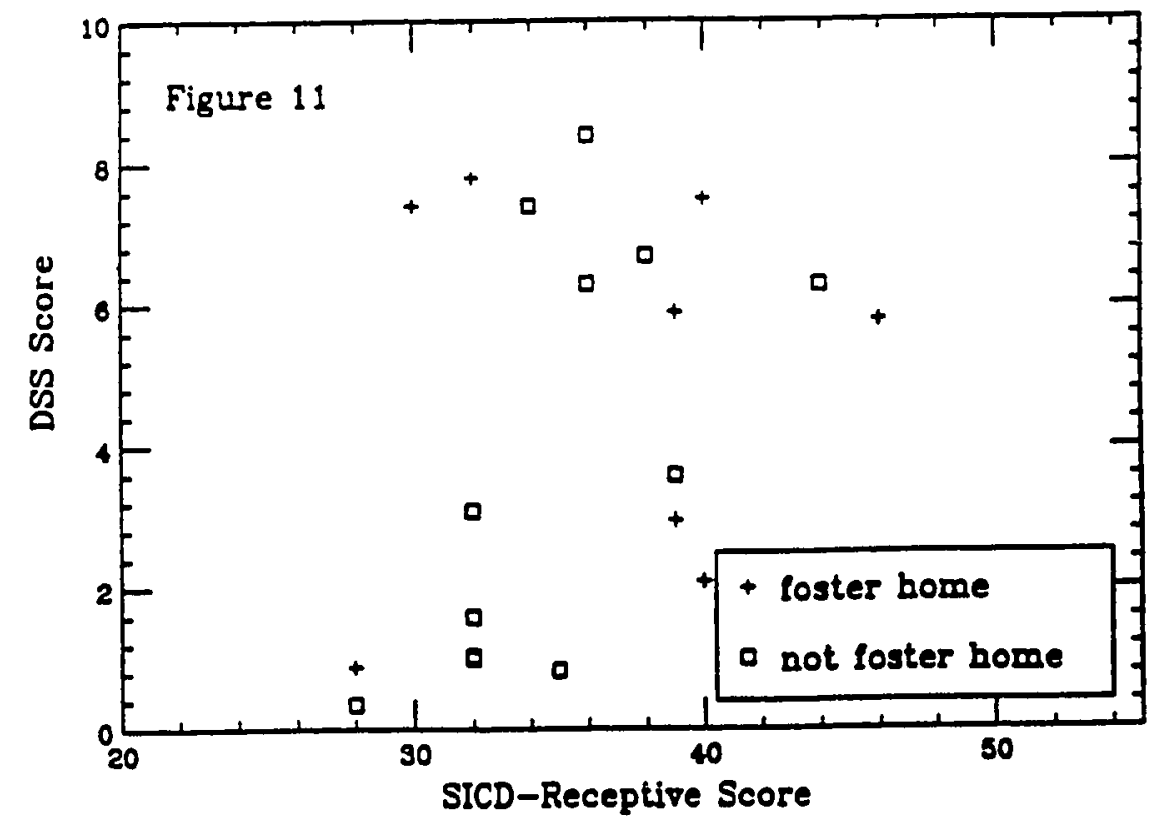

Figure 12. Performance of children from foster and non-foster homes on the DSS and the SICD - Expressive Scale.

DSS vs. SICD-Expressive Scale

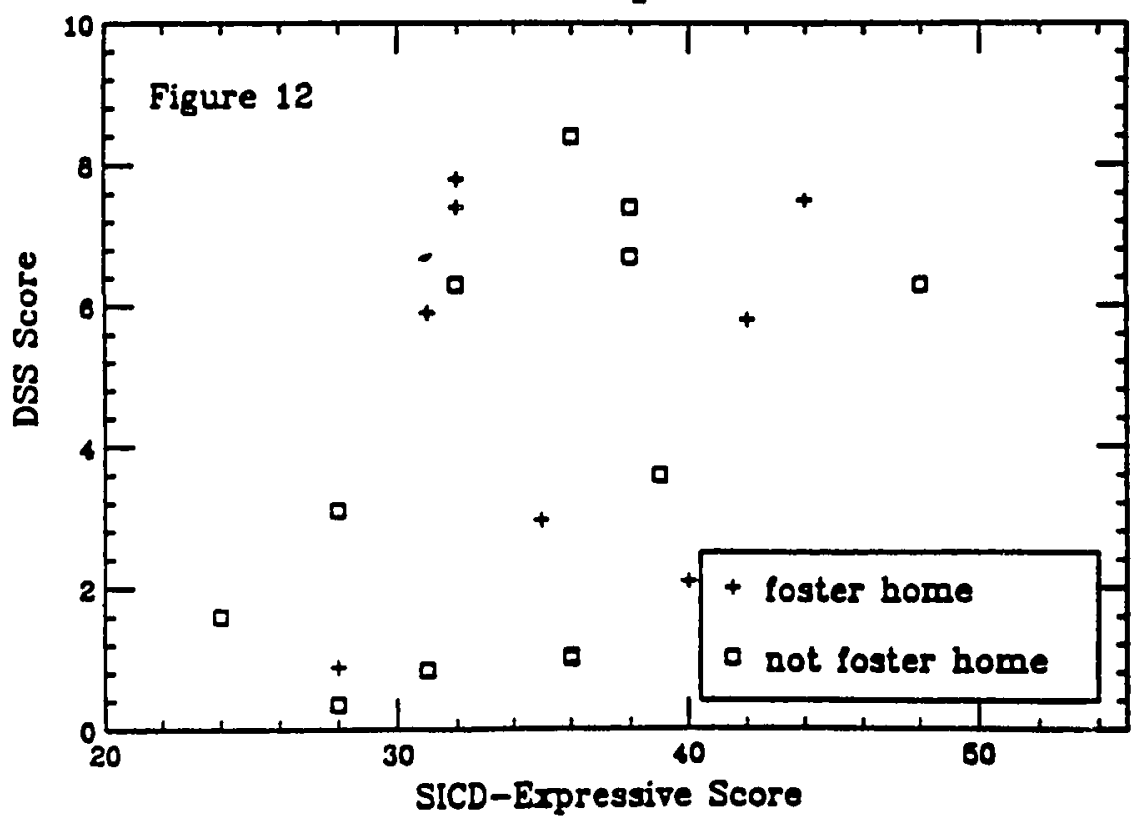


Figure 13. Performance of children from lower and middle class homes on the DSS and the PPVT-R.

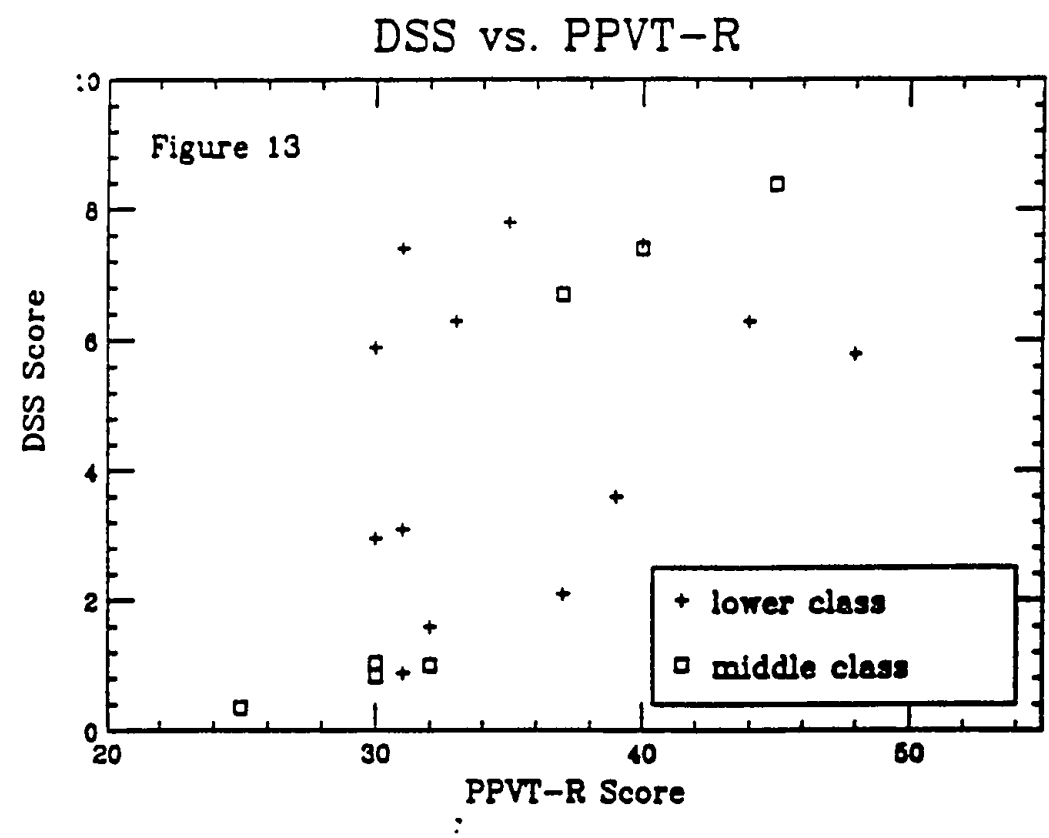

Figure 14. Performance of children from lower and middle class homes on the DSS and the EOWPVT.

DSS vs. EOWPVT

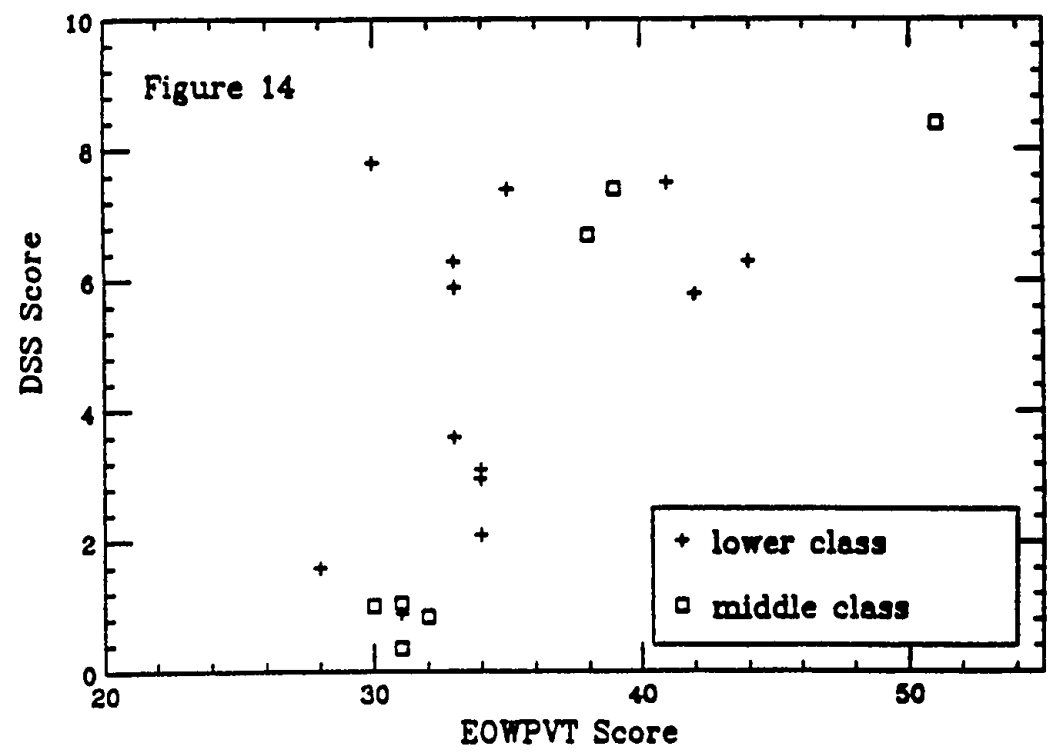


Figure 15. Performance of children from lower and middle class homes on the DSS and the SICD - Receptive Scale.

DSS vs. SICD-Receptive Scale

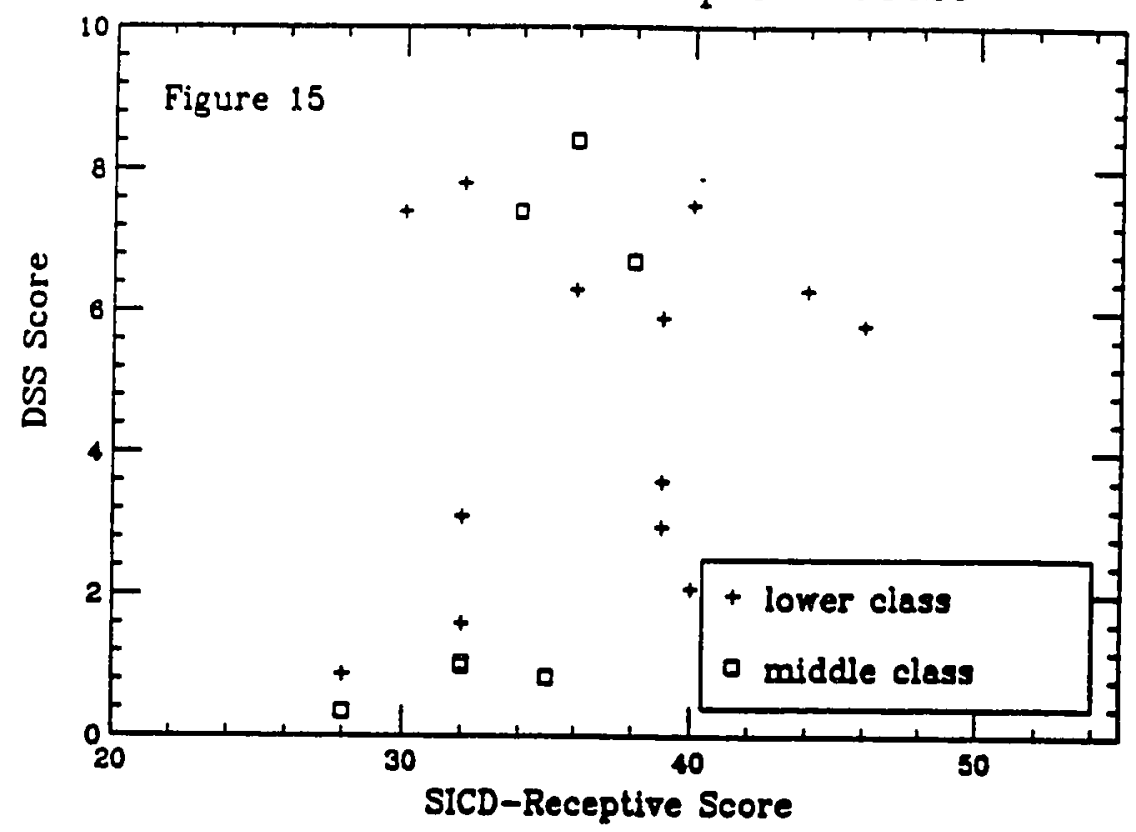

Figure 16. Performance of children from lower and middle class homes on the DSS and the SICD - Expressive Scale.

DSS vs. SICD-Expressive Scale

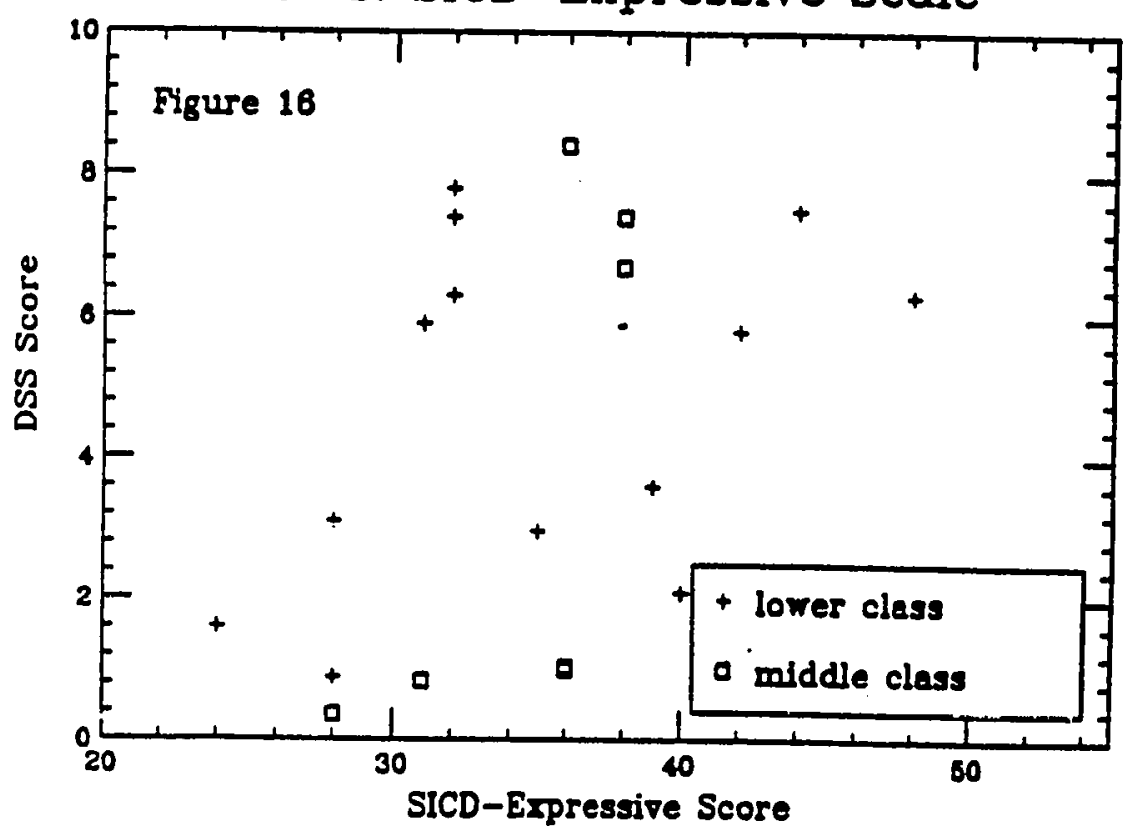




\section{CHAPTER 5}

\section{Summary}

This investigation into the relationship between scored spontaneous speech samples and speech and language test scores of preschool age children supports the hypotheses advanced in Chapter 1 . Those 10 children who were prenatally exposed to toxic substances did, in fact, perform significantly more poorly on a spontaneous speech sample than on a standardized speech and language battery. The 10 non-exposed children in the control group did not demonstrate such a disparity in their test performance. As all of the children in the study were from similar family situations and were identified as being at risk for learning and/or behavioral problems, these factors could be eliminated as confounding variables. Therefore, the family structure (single parent vs. non-single parent home), the child's status (foster home vs. nonfoster home), and the family's socioeconomic status were factors removed using a multiple regression analysis. The remaining variable, drug exposure vs. non-drug exposure, remained as significant in separating the two groups' performance.

In particular, the following hypotheses are supported in this study:

1. Performance on the DSS does correlate more strongly with drug exposure than with the PPVT-R (Form M), the EOWPVT, and the SICD. Therefore, in this study drug exposure or non-exposure is a better predictor of spontaneous speech performance than performance on a standardized speech and language battery. 
2. The DSS scores correlate more strongly with drug exposure than with the child's living situation, socioeconomic status, being in a foster home, or being in a single-parent home.

3. Once the effect of drug exposure is removed, other tests and qualitative variables measured in this study do not show a significant correlation with DSS scores.

It appears that standardized speech and language test scores may not accurately reflect exposed children's spontaneous speech production abilities and that age-equivalent or near age-equivalent expressive language test scores for exposed children do not necessarily imply that these children will have age equivalent conversation skills. Relying on standardized speech and language batteries or on variables associated with family circumstances may result in overlooking significant deficits in spontaneous speech abilities in prenatally exposed children. In particular, children may be denied speech and language services (such as school special education intervention) based solely on their performance on standardized speech and language test batteries. Without the additional component of a scored spontaneous speech sample, many prenatally exposed children may "fall through the cracks" and may therefore be denied important remediation opportunities.

\section{Implications}

Speech pathologists and others working with young children should be aware of the ramifications of discrepancies in performance and testing in drug-exposed children, revealed by this investigation. The child who appears to be comprehending, but is unable to communicate effectively through speech, may require an evaluation to determine the nature of the language 
deficit. If a profile similar to those of the drug-exposed children in this study results, the examiner may attempt to obtain additional information about the child's birth history. If it is found that the child suffered drug exposure prenatally, suggestions for remediation might include steps to reach attention, cognitive, and potential learning problems, as well as to develop vocabulary, grammatical structure, and recall for spontaneous production. If a birth history is not available, the course of remediation might involve the same concerns as those for the known exposed child, until those concerns are ruled out.

Additionally, the use of language samples to alert educators and parents to existing and potential speech problems should be reviewed. Many school districts currently do not accept language sample scores to determine a child's placement in speech therapy or special education programs. Particularly if a child scores at or above the 75th percentile on standardized speech and language tests, a low score on a language sample may be disregarded as an aberration or as a culturally influenced feature. In some cases, a low score on a language sample could reflect the fact that the child's primary language is not English. A language sample taken in the child's primary language would be essential to rule out language differences as a basis for test discrepancies. Also, a language sample culled from both the home and school setting might be more representative of the child's spontaneous production than a sample taken in the school setting alone. Children who would benefit from special services may be denied them if the discrepancies between their (culturally and linguistically appropriate) 
standardized speech and language test scores and their language sample scores are not considered possible indicators of the effects of prenatal drug exposure.

For future research, it would be valuable to perform follow-up studies on this population to determine whether gains in spontaneous speech occur over time, or whether the discrepancies remain. A longitudinal study is the next step, as the consequences of spontaneous speech deficits will have an impact not just on the lives of the exposed children and their families, but on this country's entire educational system. Speech-language pathologists, special education teachers, and regular classroom teachers at the elementary level, in particular, should be alerted. Therapeutic intervention, as well as classroom lesson strategies, may have to be adjusted to accommodate those many exposed children with specific expressive language deficits.

Another topic for future research could be an investigation into the lack of correlation between the test scores on the DSS and on the PPVT-R, the EOWPVT, and the SICD for drug-exposed children. Perhaps some aspect of one or more these tests contributes to the disparity in the exposed child's performance. It would be advantageous to rule out any such anomaly.

Roger Brown (1973) has written that, "The order of progression in knowledge of the first language, both semantic and grammatical, will prove to be approximately invariant across children learning the same language and, at a higher level of abstraction, across children learning any language" (p. 403 ). Both Brown and Lee and Koenigsknecht (1974) have proposed formulas for measuring the child's progress through the categorization of grammatical structure in spontaneous speech. Children who are delayed in their acquisition of language also progress more slowly in the rate at which 
they grasp and utilize abstract concepts in conversations. Lee and Koenigsknecht's DSS measures the child's spontaneous production of grammatical rules. These authors recommend that those children who score at or below the 10th percentile should be evaluated further to determine whether remediation is warranted. Lee and Koenigsknecht stated that a low score on this test may be indicative of a serious language disorder. All of the exposed children in this investigation scored significantly below the 10th percentile on the DSS, while none of the non-exposed children scored below the 10th percentile.

The performance of the 10 drug-exposed children in this study may pose an exception to Brown's (1973) statement. Their acquisition of linguistic knowledge as measured by the standardized tests seems to be at a more advanced level than their demonstrated use of linguistic knowledge for spontaneous speech. Proceeding through normal stages in language development, without interruption, is the privilege of the non drug-exposed child. The exposed child is likely to proceed unevenly. 
REFERENCES 
Brazelton, T. (1990, September 9). Why is America failing its children? The New York Times Magazine pp. 40-42, 50, 90.

Bresnahan, K, Brooks, C, \& Zuckerman, B. (1991). Prenatal cocaine use:

Impact on infants and mothers. Pediatric Nursing 17 123-129.

Brown, R. (1973). First language. Cambridge: Harvard University Press.

Chasnoff, I., Landres, H., \& Barrett, M. (1990). The prevalence of illicit drug or alcohol use during pregnancy and discrepancies in mandatory reporting in Pinellas County, Florida. New England Journal of Medicine 322. 1202-1206.

Chasnoff, I., Lewis, D., \& Squires, L. (1987). Cocaine intoxication in a breast fed infant. Pediatrics 80 836-838.

Dixon, S. (1989). Effects of transplacental exposure to cocaine and methamphetamine on the neonate. The Western Journal of Medicine $150,436-442$.

Dixon, S., \& Bejar, R. (1989). Echoencephalographic findings in neonates associated with maternal cocaine and methamphetamine use: Incidence and clinical correlates. The Journal of Pediatrics, 115 770-778.

Dorris, M. (1989). The broken cord. New York: Harper \& Row.

Dunn, L, \& Dunn, L (1981). Peabody picture vocabulary test - revised. Minnesota: American Guidance Service.

Emerick,L, \& Hatten, J. (1974). Diagnosis and evaluation in speech pathology. New Jersey: Prenctice-Hall, Inc.

Fox, L., Long, S., \& Langlois, A. (1988). Patterns of language comprehension deficit in abused and neglected children. Journal of Speech and Hearing Disorders, 53, 239-244. 
Fraiberg, S. (1967). The origins of human bonds. Commentary 1 1-10.

Fried, P., \& Watkinson, B. (1990). 36-and 48-month neurobehavioral followup of children prenatally exposed to marijuana, cigarettes, and alcohol. Developmental and Behavioral Pediatrics 1149 - 58.

Fulroth, R, Phillips, B., \& Durand, D. (1989). Perinatal outcomes of infants exposed to cocaine and/or heroin in utero. American lournal of Diseases of Children 143, 905-910.

Gardner, M. (1990). Expressive one-word picture vocabulary test. Los Angeles: Academic Therapy Publications.

Gerber, S. (1990). Prevention: The etiology of communicative disorders in children. New Jersey: Prentice Hall.

Griffin, D. (1988). The effects of perinatal cocaine exposure on infant neurobehavior and early maternal-infant interactions in I. Chasnoff (Ed.), Drugs, alcohol, pregnancy, and parenting. Boston: Kluwer Academic.

Hayford, S., Epps, R, Dahl-Regis, M. (1988). Behavior and development patterns in children born to heroin-addicted and methadone-addicted mothers. Lournal of the National Medical Association 80 1197-1200.

Hedrick, D., Prather, E., \& Tobin, A. (1984). Sequenced inventory of communication development. Seattle: University of Washington Press.

Howard, Judy. (1989, September). Long-term development of infants exposed prenatally to drugs. Special Currents, pp. 1-2.

Howard, J., Beckwith, L, Rodning, C., \& Kropenske, V. (1989). The development of young children of substance-abusing parents: Insights from seven years of intervention and research. Zero to Three 4 8-12. 
Iosub, S., Fuctis, M., Bingel, N. \& Gromisch, D. (1981). Fetal alcohol syndrome revisited. Pediatrics, 68 475-479.

Kaltenbach, K, \& Finnegan, L. (1989). Prenatal narcotic exposure: Perinatal and developmental effects. Neurotoxicology 10, 597-604.

Kelley, S., Walsh, J., Thompson, K (1991). Birth outcomes, health problems, and neglect with prenatal exposure to cocaine. Pediatric Nursing 17 130136.

Kobori, J., Fierriero, D., \& Golabi, M. (1989). CNS and craniofacial anomalies in infants born to cocaine abusing mothers. Clinical Research 37 196A.

Lee, L., \& Koenigsknecht, R. (1974). Developmental sentence analysis. Evanston: Northwestern University Press.

Lewis, K. (1991). Pathophysiology of prenatal drug-exposure: In utero, in the newborn, in childhood, and in agencies. Iournal of Pediatric Nursing 6 , 185-190.

Lifschitz, M., Wilson, G., O'Brien-Smith, E., \& Desmond, M. (1985). Factors affecting head growth and intellectual function in children of drug addicts. Pediatrics $\underline{75}$, 269-274.

Lively, M. (1984). Developmental sentence scoring: Common scoring errors. American Speech-Language-Hearing Association, 15 154-168.

Marascuilo, L. \& Levin, J. (1983). Multivariate statistics in the social sciences. Monterey: Brooks/Cole Publishing Company.

Meyerson, M. (1991). Speech, language, and hearing of children prenatally exposed to drugs: The need for data and direction. Clearinghouse for Drug Exposed Children, 2, 6-9. 
Neuspiel, D., \& Hamel, S. (1991). Cocaine and infant behavior.

Developmental and Behavioral Pediatrics, 12 55-61.

Oro, A, \& Dixon, S. (1987). Perinatal cocaine and methamphetamine exposure: Maternal and neonatal correlates. The Joumal of Pediatrics, 111, 571-578.

Peterson, H., \& Marquardt, T. (1990). Appraisal and diagnosis of speech and language disorders. New Jersey: Prentice Hall, Inc.

Schorr, L (1989). Within our reach New York: Anchor Books.

Shaywitz, S., Cohen, D, \& Shaywitz, B. (1980). Behavior and learning difficulties in children of normal intelligence born to alcoholic mothers. The Joumal of Pediatrics, 96 978-982.

Shonkoff, J., \& Marshall, P. (1990). Biological bases of developmental dysfunction. In S. Meisels \& J. Shonkoff (Eds.) Handbook of early childhood intervention (pp. 35-49). New York: Cambridge University Press.

Sowder, B., \& Burt, M. (1980). Children of heroin addicts. New York: Praeger Publishers.

Sparks, S. (1984a). Birth defects and speech-language disorders. San Diego: College-Hill Press.

Sparks, S. (1984b, February). Fetal alcohol syndrome. American SpeechLanguage-Hearing Association pp. 27-30.

Sparks, S. (1989). Speech and language in maltreated children: Response to McCauley and Swisher (1987). Lournal of Speech and Hearing Disorders 54. 124-125. 
Spitz, H., \& Rosecan, J. (1987). Cocaine abuse: New directions in treatment and research. New York Bruner Mazel.

Staff. (1990, August). GAO warns of "urgent" problem of drug-exposed infants in U.S. Drugs and Drug Abuse Education Newsletter 21, 77-80.

Staff. (1991, September). Preschool, school programs could help all but small core of drug-exposed children. Drug and Drug Abuse Education Newsletter $\underline{22}, 81-85$.

Ting, R., Keller, A, \& Finnegan, L (1978). Physical, neurological, and developmental assessment of infants born to methadone dependent mothers. In A. Schecter, H. Alksne, \& E. Kaufman (Eds.). Drug Abuse (pp. 755-758). New York: Marcel Dekker, Inc.

Weismer, S. (1991). Theory and practice: A principled approach to treatment of young children with specific language disorders. National Student Speech Language Hearing Association Joumal 18, 76-86.

Wilson, G., Desmond, M., \& Verniad, M. (1973). Early development of infants of heroin addicted mothers. American Journal of Diseases of Children. 126, 457-464.

Wilson, G., McCreary, R, Kean, J., \& Baxter, J. (1979). The development of preschool children of heroin-addicted mothers: A controlled study. Pediatrics 63 , 135-141. 
APPENDIXES 


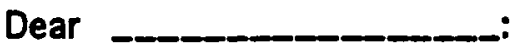

I need your help in conducting a study of the effects of prenatal exposure to toxic substances on language development in children. I am doing research in a program at San Jose State University and will be comparing language tests and speech samples of children who were exposed to drugs prenatally with language tests and speech samples of children who were not exposed. Not everyone who participates in this study has a child/ward who was exposed prenatally to toxic substances, and those children who were not exposed will serve as a control group.

I would like your permission to test your child/ward for this study during the regular time that he/she attends We Care.

Your child's name will not be used in the results if they are published. Each child in the study will be assigned a number and will be identified only by that number. I will test your child using the tests normally used at the We Care Center (Sequenced Imventory of Communication Development, Peabody Picture Vocabulary Test, Expressive One-Word Picture Vocabulary Test) and I will also record a spontaneous speech sample of 25 - 50 utterances.

You should understand that your child's participation is voluntary and that choosing not to participate in this study, or in any part of this study, will not affect your relations with We Care Center or with San Jose State University.

If you have any questions, I will be happy to talk with you. I can be reached at (510)671-0777. If you have any questions or complaints about research subject's rights, please contact Serena Stanford, Ph.D., Associate Academic Vice President for Graduate Studies and Research at San Jose State University at (408)924-2480.

I greatly appreciate your cooperation as well as your child's. Please read and sign the attached form and return it to me as soon as possible.

Sincerely,

Fran Cahn

Speech \& Language Specialist 


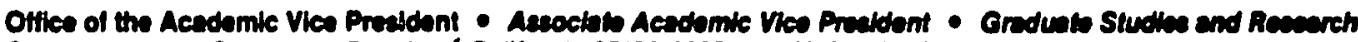

One Washington Square • San Jose, California 95192-0025 • 408/924-2480

\section{Agreement to Participate in Research}

Responsible Investigator: Fran Cahn

Title of Protocol: A comparison between spontaneous speech and standardized speech and language test scores in children with prenatal exposure to toxic substances and in children without prenatal exposure to toxic substances.

I. My child/ward has been asked to participate in a research study. The study will investigate the effects of prenatal exposure to toxic substances on speech and language test scores. Test scores of children who were not exposed prenatally to toxic substances will be compared with the test scores of those children who were exposed. My child/ward may be in the control group (the group of children who were NOT exposed prenatally to toxic substances) or the experimental group (the group of children who were prenatally exposed). Therefore, not everyone who participates in this study has a child/ward who was exposed prenatally to toxic substances.

2. My child/ward will be asked to participate in 4 different tests. These tests include the Sequenced Inventory of Communication Development, the Peabody Picture Vocabulary Test, the Expressive One-Word Picture Vocabulary Test, and a spontaneous language sample will be recorded. The tests will be administered during the hours of 9 a.m. - 1 p.m., when my child is normally at the We Care Center, Monday - Friday. The tests will be administered in the office of the Speech Therapist.

3. No risks are anticipated during this study.

4. No discernible benefits, beyond further knowledge of the origin of language disorders in children, are expected.

5. My child/ward's confidential records at the We Care Center will be released to Frances Cahn for the purposes of this study. The information in my child/ward's records may include: prenatal, birth and medical information, social history, evaluations, psychological, physical/occupational therapy, hearing, speech and language, and program information. This information will not be shared by the investigator with any other agencies or other individuals. The speech and language test results of this study may be published but no information that could identify my child will be included.

6. Questions about this research should be directed to Frances Cahn at (510)6710777. Complaints about the research may be presented to Dr. Gloria Weddington, Director, Communication Disorders and Sciences Program, San Jose State University (408) 924-3688. Questions or complaints about research, subjects' rights, or research related injury (none anticipated) may be presented to Serena Stanford, Ph.D., Associate Vice President of Graduate Studies and Research, at (408)924-2480.

7. The usual services that my child receives at We Care Center will not be lost or jeopardized if my child/ward chooses not to participate in the study. 
8. My consent is given voluntarily. My child/ward may refuse to participate in the study or any part of the study. If my child/ward decides to participate in the study, he/she is free to withdraw at any time without prejudice to his/her relations with San Jose State University or the We Care Center.

9. My child/ward has received a signed and dated copy of the consent form.

The signature of a parent/guardian on this document indicates agreement to participate in the study.

The signature of a researcher on this document indicates agreement to include the below named subject in the research, and attestation that the subject has been fully informed of his or her rights.

\begin{tabular}{ll} 
Child/Ward's Name (Subject) & Date \\
\hline Parent/Guardian's Signature & Date \\
\hline Imvestigator's Signature & Date
\end{tabular}

